\title{
Bulk and Surface Aqueous Speciation of Calcite: Implications for Low-Salinity Waterflooding of Carbonate Reservoirs
}

\author{
Maxim P. Yutkin, Himanshu Mishra, and Tadeusz W. Patzek, King Abdullah University of Science and Technology; \\ John Lee and Clayton J. Radke, University of California
}

\begin{abstract}
Summary
Low-salinity waterflooding (LSW) is ineffective when reservoir rock is strongly water-wet or when crude oil is not asphaltenic. Success of LSW relies heavily on the ability of injected brine to alter surface chemistry of reservoir crude-oil brine/rock (COBR) interfaces. Implementation of LSW in carbonate reservoirs is especially challenging because of high reservoir-brine salinity and, more importantly, because of high reactivity of the rock minerals. Both features complicate understanding of the COBR surface chemistries pertinent to successful LSW. Here, we tackle the complex physicochemical processes in chemically active carbonates flooded with diluted brine that is saturated with atmospheric carbon dioxide $\left(\mathrm{CO}_{2}\right)$ and possibly supplemented with additional ionic species, such as sulfates or phosphates.

When waterflooding carbonate reservoirs, rock equilibrates with the injected brine over short distances. Injected-brine ion speciation is shifted substantially in the presence of reactive carbonate rock. Our new calculations demonstrate that rock-equilibrated aqueous $\mathrm{pH}$ is slightly alkaline quite independent of injected-brine $\mathrm{pH}$. We establish, for the first time, that $\mathrm{CO}_{2}$ content of a carbonate reservoir, originating from $\mathrm{CO}_{2}$-rich crude oil and gas, plays a dominant role in setting aqueous $\mathrm{pH}$ and rock-surface speciation.

A simple ion-complexing model predicts the calcite-surface charge as a function of composition of reservoir brine. The surface charge of calcite may be positive or negative, depending on speciation of reservoir brine in contact with the calcite. There is no single point of zero charge; all dissolved aqueous species are charge determining. Rock-equilibrated aqueous composition controls the calcitesurface ion-exchange behavior, not the injected-brine composition. At high ionic strength, the electrical double layer collapses and is no longer diffuse. All surface charges are located directly in the inner and outer Helmholtz planes.

Our evaluation of calcite bulk and surface equilibria draws several important inferences about the proposed LSW oil-recovery mechanisms. Diffuse double-layer expansion (DLE) is impossible for brine ionic strength greater than 0.1 molar. Because of rapid rock/brine equilibration, the dissolution mechanism for releasing adhered oil is eliminated. Also, fines mobilization and concomitant oil release cannot occur because there are few loose fines and clays in a majority of carbonates. LSW cannot be a low-interfacial-tension alkaline flood because carbonate dissolution exhausts all injected base near the wellbore and lowers $\mathrm{pH}$ to that set by the rock and by formation $\mathrm{CO}_{2}$. In spite of diffuse double-layer collapse in carbonate reservoirs, surface ion-exchange oil release remains feasible, but unproved.
\end{abstract}

\section{Introduction}

LSW refers to improved oil recovery achieved by waterflooding a reservoir with brine of lower salinity than that of the field brine. The process is alluring because of simplicity, favorable economics, and large potential. In some applications, seawater is injected, a fluid not commonly viewed as "low" salinity. Precise definition of LSW is lacking. In principle, spiking injection water with specific anions and/or cations has the potential to improve recovery (Strand et al. 2006; Zhang et al. 2007b; Sorbie and Collins 2010; Alshakhs and Kovscek 2015; Austad et al. 2015; Puntervold et al. 2015) without need for lower salinity.

Starting in the middle 1990s, the pioneering work of Morrow and colleagues popularized LSW of sandstones. Fines release was highlighted as one of several proposed recovery mechanisms (Jadhunandan and Morrow 1995; Yildiz and Morrow 1996; Tang and Morrow 1997, 1999, 2002; Zhang and Morrow 2006; Zhang et al. 2007b). Later studies of LSW in sandstones (Webb et al. 2004; Lager et al. 2007, 2008a, b) confirmed the oil-recovery findings of Yildiz and Morrow (1996), but did not experimentally observe fines release. These authors (Webb et al. 2004; Lager et al. 2007, 2008a, b) introduced multicomponent ion exchange (MIE) from which oil releases by aqueous ions exchanging at the rock surface.

LSW of carbonate reservoirs, the focus of this work, was initially dismissed because carbonate rock typically contains no clays. Austad and coworkers, however, showed a positive response of carbonate rocks to LSW (Zhang and Austad 2006; Strand et al. 2006; Zhang et al. 2007a; Rezaeidoust et al. 2009; Fathi et al. 2010; Puntervold et al. 2015). These authors also promulgated a version of MIE as an LSW oil-recovery mechanism. In a landmark contribution, Yousef et al. (2011) detailed the viability of LSW with seawater in a Middle East carbonate. Later works experimentally confirm the earlier findings of successful oil recovery by LSW in carbonate rock (Zahid et al. 2012; Chandrasekhar and Mohanty 2013; Alshakhs and Kovscek 2015).

Several helpful reviews on LSW are available (Lager et al. 2008a; Buckley and Morrow 2010; Morrow and Buckley 2013; Sheng 2014; Myint and Firoozabadi 2015). Fascinatingly, Sheng (2014) introduced 15 disparate physical mechanisms for LSW oil displacement. Multiple and coupled mechanisms likely conspire. Definitive confirmatory experiments are lacking. Nevertheless, there is consensus on three observations:

- LSW recovers only crude oil. Improved recovery with clean oils is not found.

- Some wettability alteration toward more-water-wet rock is requisite, but not complete water-wetting (Brady et al. 2015).

- Rock/water interactions are important.

The surface charge of the mineral interfaces appears to play a critical role. This last observation engendered a large number of ancillary studies on silica, clay, and calcite/water interfaces and their ion-exchange behavior, especially recently (Lager et al. 2008a; Sorbie and Collins 2010; Nasralla and Nasr-El-Din 2012; Alotaibi et al. 2011; Alotaibi and Yousef 2015; Alshakhs and Kovscek 2015; Brady

Copyright $(2017$ Society of Petroleum Engineers

This paper (SPE 182829) was accepted for presentation at the SPE Kingdom of Saudi Arabia Annual Technical Symposium and Exhibition, Dammam, Saudi Arabia, 25-28 April 2016, and revised for publication. Original manuscript received for review 31 August 2016. Revised manuscript received for review 6 April 2017 . Paper peer approved 10 April 2017. 
et al. 2015; Myint and Firoozabadi 2015; Puntervold et al. 2015; Qiao et al. 2016). Fundamental studies (Ricci et al. 2013; Alshakhs and Kovscek 2015; Brady et al. 2015; Lashkarbolooki et al. 2016; Mugele et al. 2016) of the calcite/water interface, including molecular simulation (Kerisit and Parker 2004; Sakuma et al. 2014; Qiao et al. 2016), also garnered attention. These results generally support the surface-charge-recovery concepts of DLE and MIE.

Carbonate reservoirs are unique in several ways. Foremost, carbonate rock is "reactive" in that it alters the injected-brine composition by dissolution/precipitation. In particular, we demonstrate that injected brine almost immediately equilibrates with carbonate rock. Thus, the assessment of aqueous speciation chemistry is paramount to LSW (Al-Shalabi et al. 2014; Qiao et al. 2014, 2016). Also pertinent to LSW in carbonates are high-salinity brine and lack of clay content, both of which affect the DLE recovery mechanism.

Because LSW strongly depends on rock/brine chemistry, this paper also ascertains the equilibrium compositions of the calcitemineral/water interface, appropriate to reservoir brine compositions. We discover that aqueous $\mathrm{CO}_{2}$ in the reservoir is critical to rock/ brine equilibria. Reservoir sources of aqueous $\mathrm{CO}_{2}$ are injected seawater saturated with atmospheric $\mathrm{CO}_{2}$ at $350 \mathrm{ppm}\left(10^{-3.44}\right.$ bar), $\mathrm{CO}_{2}$-saturated crude oil, and, at times, $\mathrm{CO}_{2}$-rich gas phase. Because aqueous $\mathrm{CO}_{2}$ is such an important driver of carbonate equilibria, its effect is investigated over a broad range of concentrations. Aqueous $\mathrm{CO}_{2}$ concentration in the reservoir is varied from essentially zero $\left(10^{-8} \mathrm{~mol} / \mathrm{L}\right)$ to very high $(1 \mathrm{~mol} / \mathrm{L})$. Importance of the specific crude oil cannot be ignored, but here we focus on rock/brine interactions in promoting LSW oil recovery.

In the following sections, we establish that equilibrium reaction with calcite rock controls brine composition in the reservoir. An important corollary is that for all laboratory experiments involving water in carbonate rocks, the aqueous brine must be pre-equilibrated. Following this discussion, we demonstrate the importance of aqueous speciation in controlling surface-charge behavior under reservoir conditions. We conclude by summarizing how surface and bulk aqueous speciation negate many of the proposed mechanisms by which LSW is anticipated to perform.

\section{Methodology}

Calcite/Solution Kinetics. Carbonate rocks consist mainly of crystalline calcite, and include smaller amounts of dolomite, anhydride, and dolostone (Folk 1959, 1962; Lucia 2007). Because these minerals exhibit significant water solubility, they are considered "reactive," meaning that rock dissolves/precipitates under the influence of water chemistry (Stumm and Morgan 1996; Sposito 2008). Given sufficient exposure time, carbonate rock equilibrates with the surrounding aqueous phase. Fig. 1 shows the injection of an aqueous electrolyte solution into a porous carbonate rock. Inlet species molar concentration is $C_{i 0}$, where the tilde under $C$ denotes a vector of species. During traverse through the rock, the aqueous ionic species react with mineral surfaces (Fig. 1). Upon exiting the porous rock at $z=L$, the aqueous-species concentrations adjust to new values, $C_{i L}$. Fig. 1 illustrates that aqueous carbonate species appear at the outlet face, although they are not injected. For a long-enough porous medium, the aqueous solution eventually saturates at mineral equilibrium.

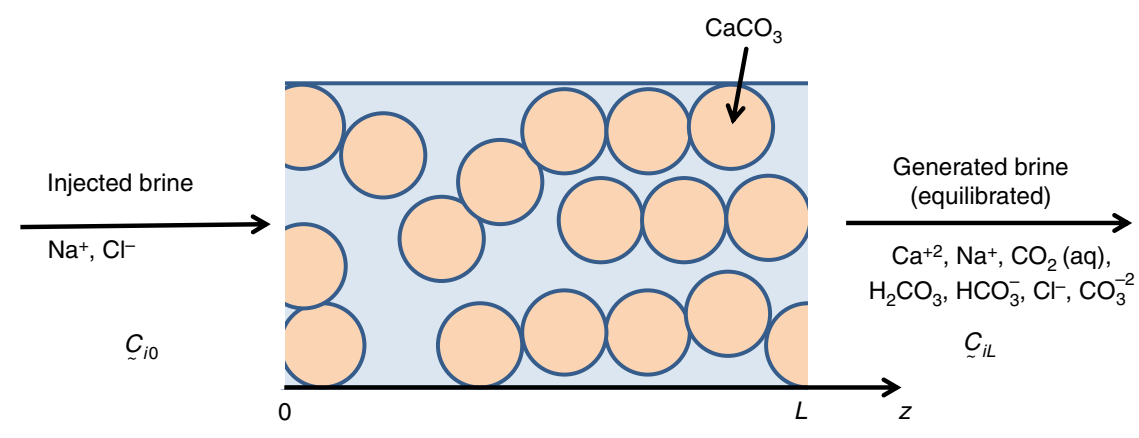

Fig. 1-Equilibration of injected brine with carbonate rock of length $L$. Aqueous species are produced from mineral dissolution/ precipitation quickly reaching equilibrium. Light-brown circles denote calcite, and the blue background denotes brine.

Rock/brine equilibration occurs when the residence time in the porous medium, $t_{\text {res }}$, is longer than the characteristic rock-dissolution time, $t_{\mathrm{dis}}$. Specifically, when $t_{\mathrm{dis}} / t_{\mathrm{res}}<1$, equilibrium prevails and vice versa. The ratio $t_{\text {res }} / t_{\mathrm{dis}}$ is defined as the Damköhler number: $D a \equiv t_{\text {res }} / t_{\text {dis }}$ (Bird et al. 2007; Kim and Santamarina 2016). Consequently, when $D a<1$, dissolution kinetics governs reservoir behavior (Lu et al. 2016), whereas $D a>1$ means local equilibrium is achieved, or

$D a<1$, kinetic control

$D a>1$, equilibrium control.

Dissolution/precipitation kinetics establishes how fast the rock equilibrates. Appendix A outlines a simple expression for the kinetics of calcite dissolution and estimates $t_{\text {dis }}$ appropriate to a fractured calcium carbonate reservoir rock. We find that $t_{\text {dis }}$ is less than a few seconds both in fractures and in low-permeability matrix blocks, independent of the frontal advance rate.

Residence time in the porous medium, $t_{\text {res }}$, is estimated as $L / v$, where $L$ and $v$ are characteristic length and velocity, respectively. In fractures, $v=u$, the injected frontal advance rate, and $L$ is the penetration depth into the porous medium. Conversely, in the matrix, $v$ is the imbibition-flow velocity, and $L$ is the penetration depth into the matrix block. In obedience to Eq. 1, equilibrium occurs when

$L>v t_{\text {dis }}$.

Consider first the rock dissolution in fractures. For a frontal advance rate of $u=100 \mathrm{ft} / \mathrm{D}$, we find that brine carried in fractures equilibrates with the rock within a few millimeters of penetration depth, at most. For fluid imbibing into matrix blocks at a high advance rate of $1 \mathrm{ft} / \mathrm{D}$, Eq. 2 specifies a matrix-penetration distance of $5 \mu \mathrm{m}$, beyond which brine is in equilibrium with calcite rock. Carbonate-rock equilibration with a flowing aqueous phase is practically instantaneous. This conclusion holds also for forced-imbibition corefloods. 
The fast kinetics of carbonate dissolution is important. First, carbonate rocks equilibrate with the flooding solution over extremely short distances. Similarly, laboratory core plugs a few centimeters in length come into equilibrium with the waterflooding solution. Second, injected-brine composition is not what occurs in the pores of the medium. In LSW, reactive rock changes the injected-brine composition substantially, a fact that is not normally considered. Third, changes in aqueous composition are critical to LSW because of the sensitivity of the process to water chemistry. To understand the role of ion-complexing surface chemistry in LSW, a detailed understanding of the rock/aqueous-solution equilibria is mandatory. Fourth, the proposed "rock-dissolution" mechanism of LSW-improved oil recovery (Buckley and Morrow 2010; Hiorth et al. 2010; Zahid et al. 2012; Al-Shalabi et al. 2014; Lashkarbolooki et al. 2016) is not applicable (unless the injected brine completely dissolves the rock). Injected brine equilibrates with carbonate rock almost immediately after exiting the injection well. Thereafter, the rock no longer dissolves (or precipitates) and can no longer etch to release oil. The fact that carbonates equilibrate rapidly with brine necessitates a detailed understanding of aqueous-speciation chemistry (Al-Shalabi et al. 2014; Alotaibi and Yousef 2015; Qiao et al. 2014, 2016).

Calcite/Solution Bulk Equilibria. The chemistry of calcite/water equilibrium involves numerous aqueous species. Fortunately, considerable information is available (Stumm and Morgan 1996). Appendix B lists the currently accepted species reactions and corresponding equilibrium constants at ambient temperature (Charlton and Parkhurst 2011; Al-Shalabi et al. 2014; Parkhurst and Apello 2014; Qiao et al. 2016). When rock equilibration is achieved, species chemical-reaction equilibria are obeyed (Felder et al. 2015):

$$
K_{j}(T)=\prod_{i}\left(\gamma_{i} C_{i L}\right)^{\nu_{i j}}
$$

where $K_{j}(T)$ is the $j$ th reaction equilibrium constant at temperature $T$, and $\gamma_{i}$ is the dilute-solution activity coefficient of species $i$ ( $\gamma_{i}$ approaches unity as concentrations approach zero). Element mass balance completes the equilibrium calculation (Charlton and Parkhurst 2011; Al-Shalabi et al. 2014; Parkhurst and Apello 2014; Felder et al. 2015):

$$
C_{i L}=C_{i 0}+\sum_{j} \nu_{i j} \xi_{j}
$$

where the subscript $j$ denotes the $j$ th independent chemical reaction, $\xi_{j}$ is the extent of the $j$ th reaction (Felder et al. 2015) (in mol/L), and $\nu_{i j}$ is the stoichiometric coefficient of species $i$ in reaction $j$. Eq. 4 means that species concentrations exiting the porous medium are those entering plus those produced (or consumed) by chemical reaction with minerals. Imposition of solution electroneutrality is unnecessary because all speciation reactions conserve charge (Stumm and Morgan 1996; Al-Shalabi et al. 2014). Substitution of Eq. 4 into Eq. 3 yields coupled nonlinear algebraic expressions to calculate the extent-of-reaction vector $\xi$. Eq. 4 then establishes the equilibrium-species concentrations $C_{i L}$. On the basis of the available species identifications (Al-Shalabi et al. 2014), our calculation of calcite/ sodium chloride $(\mathrm{NaCl})$ brine chemistry specifies 10 independent equilibrium reactions, as listed in Table 1. Given reaction stoichiometry, equilibrium constants, and activity coefficients, Eqs. 3 and 4 are solved simultaneously by two different numerical methods. First, Newton iteration is used in MATLAB (2015). Second, PHREEQC software (Charlton and Parkhurst 2011; Parkhurst and Apello 2014) is adopted. Excellent agreement is found between the two procedures. Appendix B details the numerical solutions.

\begin{tabular}{cccc} 
No. & Reaction & $\log _{10} \mathrm{~K}$ & Units \\
\hline 1 & $\mathrm{CO}_{2(\mathrm{~g})} \rightleftarrows \mathrm{CO}_{2(\mathrm{aq})}$ & -1.47 & $\mathrm{~mol} / \mathrm{L} \mathrm{atm}$ \\
2 & $\mathrm{CO}_{2(\mathrm{aq})}+\mathrm{H}_{2} \mathrm{O} \rightleftarrows \mathrm{H}_{2} \mathrm{CO}_{3}$ & -2.59 & - \\
3 & $\mathrm{H}_{2} \mathrm{CO}_{3} \rightleftarrows \mathrm{H}^{+}+\mathrm{HCO}_{3}^{-}$ & -3.76 & $\mathrm{~mol} / \mathrm{L}$ \\
4 & $\mathrm{HCO}_{3}^{-} \rightleftarrows \mathrm{H}^{+}+\mathrm{CO}_{3}^{2-}$ & -10.33 & $\mathrm{~mol} / \mathrm{L}$ \\
5 & $\mathrm{H}_{2} \mathrm{O} \rightleftarrows \mathrm{H}^{+}+\mathrm{OH}^{-}$ & -14 & $(\mathrm{~mol} / \mathrm{L})^{2}$ \\
6 & $\mathrm{CaCO}_{3(\mathrm{~s})} \rightleftarrows \mathrm{Ca}^{2+}+\mathrm{CO}_{3}^{2-}$ & -8.48 & $(\mathrm{~mol} / \mathrm{L})^{2}$ \\
7 & $\mathrm{CaOH}^{+} \rightleftarrows \mathrm{Ca}^{2+}+\mathrm{OH}^{-}$ & -1.22 & $\mathrm{~mol} / \mathrm{L}$ \\
8 & $\mathrm{CaHCO}_{3}^{+} \rightleftarrows \mathrm{Ca}^{2+}+\mathrm{HCO}_{3}^{-}$ & -1.11 & $\mathrm{~mol} / \mathrm{L}$ \\
9 & $\mathrm{NaHCO}_{3} \rightleftarrows \mathrm{Na}^{+}+\mathrm{HCO}_{3}^{-}$ & 0.25 & $\mathrm{~mol} / \mathrm{L}$ \\
10 & $\mathrm{NaCO}_{3}^{-} \rightleftarrows \mathrm{Na}^{+}+\mathrm{CO}_{3}^{2-}$ & -1.27 & $\mathrm{~mol} / \mathrm{L}$ \\
\hline
\end{tabular}

Table 1-Solution-equilibrium reactions and equilibrium constants, $K(298 \mathrm{~K})$. The $\log _{10} K$ values are from Charlton and Parkhurst (2011) and Parkhurst and Apello (2014).

Calcite/Solution Surface Equilibria. Because of the proposed importance of the aqueous-calcite surface charge to the LSW process, elucidation of surface equilibria is paramount. Atomic structure of the calcite/water interface has been extensively studied, specifically the [104]-face, because it is predominant (Fenter et al. 2000; Pokrovsky et al. 2000; Geissbühler et al. 2004; Kerisit and Parker 2004; Heberling et al. 2011; Ricci et al. 2013; Sakuma et al. 2014). We adopt the corresponding [104]-interface structure shown in Fig. 2, which reveals that all surface carbonate ions are raised and tilted so they are slightly out of plane. Each surface calcium ion is surrounded by six carbonate anions in an octahedral arrangement. In turn, each carbonate-anion-exchange site is surrounded by six calcium cations; bulk calcite is electroneutral. Because of lattice termination, calcium ions at the aqueous/solid interface exhibit one (crystal face), two (edge), or three (corner) labile coordination bonds. Similar reasoning holds for the lattice-terminated carbonate ions. Upon assuming $\frac{1}{3}$ elemental charge for each broken lattice bond (Hiorth et al. 2010), the charge arising on each surface-lattice ion is in the range from $\frac{1}{3}$ to $1 F$ ( $F=$ Faraday's constant, in $\mathrm{C} / \mathrm{mol})$, negative for carbonate and positive for calcium. This observation explains the noninteger 
surface charges adopted by Heberling et al. (2011) for the calcite/water interface. We do not account for edge and corner sites but invoke surface-charge numbers of \pm 1 . From the crystal-lattice structure, the maximum number of ion-exchange sites on a [104]-calcite surface is $5 \mathrm{~nm}^{-2}$ each for calcium and carbonate sites. This value was experimentally confirmed by Möller and Sastri (1974). We picture the calcite/water interface as electroneutral but with equal and opposite cationic- and anionic-exchange charge densities of $\pm 80 \mu \mathrm{C} / \mathrm{cm}^{2}$.

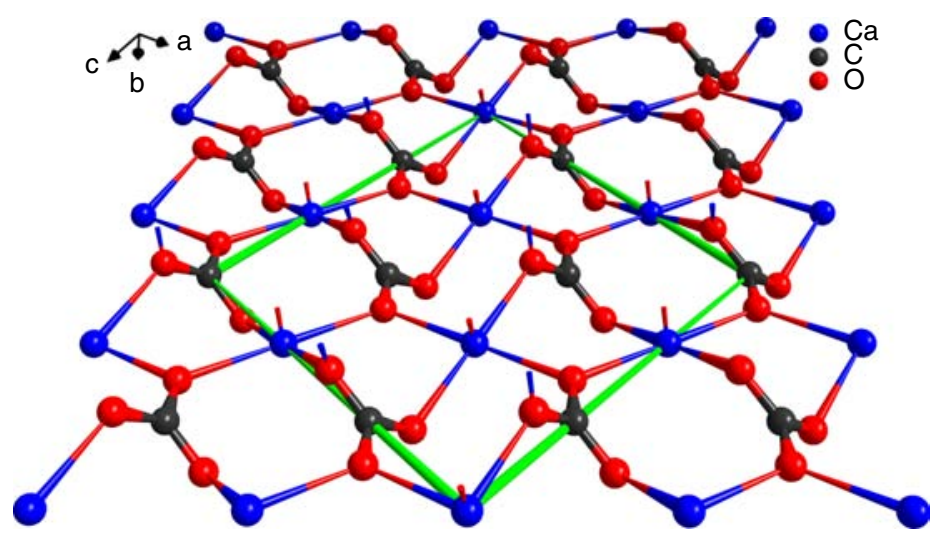

Fig. 2-A view of calcite [104]-crystal plane. Red balls are oxygen, blue balls are calcium, and black balls are carbon. Green lines indicate real crystal edges and have length of $0.95 \mathrm{~nm}$. Beneath the plane is bulk calcite and above the plane is the interface, which is indicated by truncated bonds within the square bounded by green lines. There are five ion-exchange sites of calcium and carbonate per $\mathrm{nm}^{2}$. These are counted the following way: two calcium from the center of the square (face calcium) plus $\frac{4}{2}$ calcium from the edges of the square (edge calcium), and plus $\frac{2}{4}$ from the corners (corner calcium) gives 4.5 calcium sites per $0.9025 \mathrm{~nm}^{2}$. Extrapolating this number gives 5 sites $/ \mathrm{nm}^{2}$.

Fig. 3a is a schematic of ions distributed near the calcite surface. As discussed previously, the lattice surface, or 0-plane, is on average electrically neutral, demanding a net surface-charge density of $\sigma_{0}=0$. Nevertheless, the calcite/water interface acquires charge in the presence of aqueous electrolytes because of the specific adsorption of charge-bearing aqueous species. For simple aqueous electrolytes, specific adsorption occurs primarily by ion complexation or ion binding with oppositely charged surface sites. Calcite immersed in water is both a cation- and anion-exchange mineral. Because all aqueous ionic species potentially exchange, there is no one potentialor charge-determining ion (Somasundaran and Agar 1967; Thompson and Pownall 1989; Pierre et al. 1990; Zhang and Austad 2006; Zhang et al. 2007a). Because the proclivity for exchange is not the same for all aqueous ions, a nonzero surface-charge density, $\sigma_{\beta}$, arises at the $\beta$-plane or inner Helmholtz plane (Grahame 1947; Newman and Thomas-Alyea 2004; Berg 2010). The remaining charge at the surface is distributed in the diffuse electrical double layer, commencing at the $d$-layer or the outer Helmholtz plane, highlighted in Fig. 3a. Because the calcite/water interface at the 0-plane is neutral, the charge density in the diffuse electrical double layer, $\sigma_{d}$, balances that in the $\beta$-plane (i.e., $\sigma_{\beta}+\sigma_{d}=0$ ).

In this work, ion complexing or ion binding of a solution counter ion with the oppositely charged surface site involves a significantenough specific chemical interaction to dehydrate partially the complexing ion. Conversely, all ions in the diffuse region remain fully hydrated. This feature is illustrated in Fig. 3a: Ions in the $\beta$-plane are closer to the calcite-exchanging ions and are partially dehydrated, whereas ions in the diffuse layer are fully hydrated. Of course, ions have different hydrated sizes so that the $\beta$ - and $d$-planes are not strictly uniform layers. Our analysis does not include this detail (Levine et al. 1967).

Following others (Davis et al. 1978; Dzombak and Morel 1990; Hiemstra and Riemsdijk 1996), we recognize surface-ion complexing as an equilibrium chemical reaction analogous to Eq. 3, but expressed with surface concentration for each surface complex. Because all aqueous ions potentially exchange at calcite-surface sites, a large number of surface complexes is possible. Fortunately, considerable information is available on the calcite/water interface (Somasundaran and Agar 1967; Möller and Werr 1972; Siffert and Fimbel 1984; Thompson and Pownall 1989; Van Cappellen et al. 1993; Pokrovsky et al. 2000; Nystrom 2001; Wolthers et al. 2008; Hiorth et al. 2010; Alotaibi et al. 2011; Heberling et al. 2011; Alshakhs and Kovscek 2015). We adopt the five preliminary surface reactions listed in Table 2, where the symbol $>$ denotes surface species.

Table 1 reveals that many ionic species are present in the calcite-equilibrated brine and may ion exchange at the calcite/water interface. In particular, sodium and chloride ions are dominant species at high brine concentrations and may participate in ion-exchange equilibria. It is commonly accepted, however, that sodium and chloride ions are inactive at the calcite/water interface (Somasundaran and Agar 1967; Möller and Werr 1972; Siffert and Fimbel 1984; Thompson and Pownall 1989; Van Cappellen et al. 1993; Pokrovsky et al. 2000; Nystrom 2001; Wolthers et al. 2008; Hiorth et al. 2010; Alotaibi et al. 2011; Heberling et al. 2011; Austad et al. 2015; Puntervold et al. 2015). Unfortunately, no direct evidence is available to confirm or refute this view.

The five surface reactions listed in Table 2 are based on previous modeling of measured $\zeta$-potentials (Van Cappellen et al. 1993; Pokrovsky et al. 2000; Nystrom 2001; Wolthers et al. 2008; Hiorth et al. 2010; Alotaibi et al. 2011; Heberling et al. 2011); each has been identified by separate spectroscopic studies (Pokrovsky et al. 2000; Heberling et al. 2011). Also, except for sodium and chloride ions, these are the dominant aqueous species in calcite-equilibrated waterflooding, as shown below. Inclusion of additional surfacecomplexing reactions awaits experimental justification.

We write mass-action equilibrium expressions for the surface reactions in a surface-complexation model (SCM). For example, for the first surface reaction, $S_{1}$ in Table 2 , reaction equilibrium gives

$$
K_{S_{1}}(T)=\frac{(>\mathrm{CaOH}) \gamma_{\mathrm{H}^{+}} C_{\mathrm{H}^{+}} \exp \left(\frac{-F \varphi_{\beta}}{R T}\right)}{\left(>\mathrm{CaH}_{2} \mathrm{O}^{+}\right)},
$$

where $K_{S_{1}}$ is the surface-ion-complexing equilibrium constant, the symbol $>$ stands for surface species in the 0 - or $\beta$-planes, and parentheses denote surface concentrations in mol per area. $\gamma_{H^{+}}$is the activity coefficient of hydronium ion in solution, and 
$\varphi_{\beta}$ is the electrostatic potential at the $\beta$-plane (also at the 0 -plane in Fig. 3b). The exponential factor is a Boltzmann-activity correction to account for the electrostatics of the charged $>\mathrm{CaH}_{2} \mathrm{O}^{+}$sites. Similarly, mass-action equations are written for reactions $S_{2}$ through $S_{5}$ (Table 2 and Appendix C). Determination of the surface-complexing equilibrium constants, $K_{S_{i}}$, is discussed in the Results section.

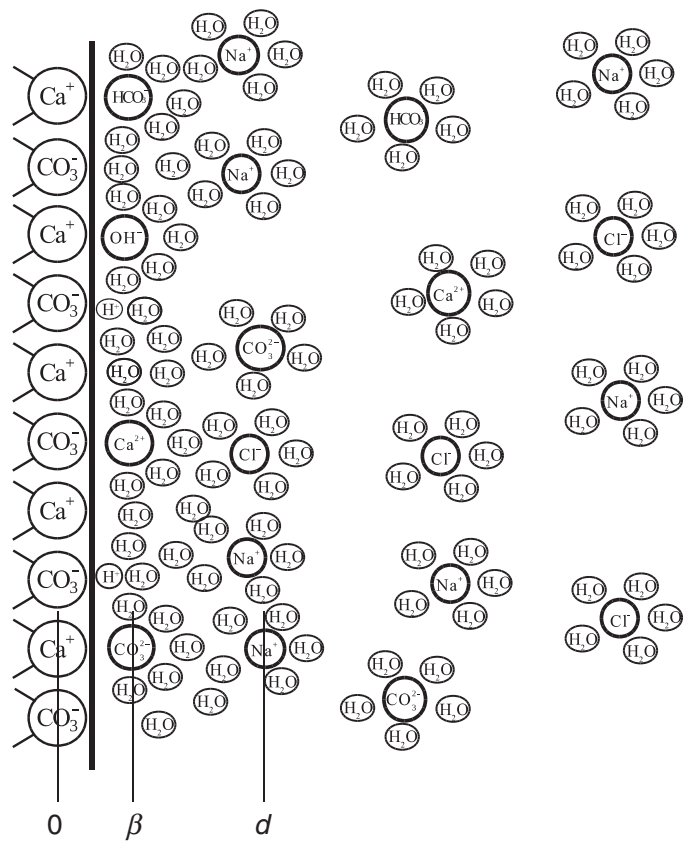

(a)

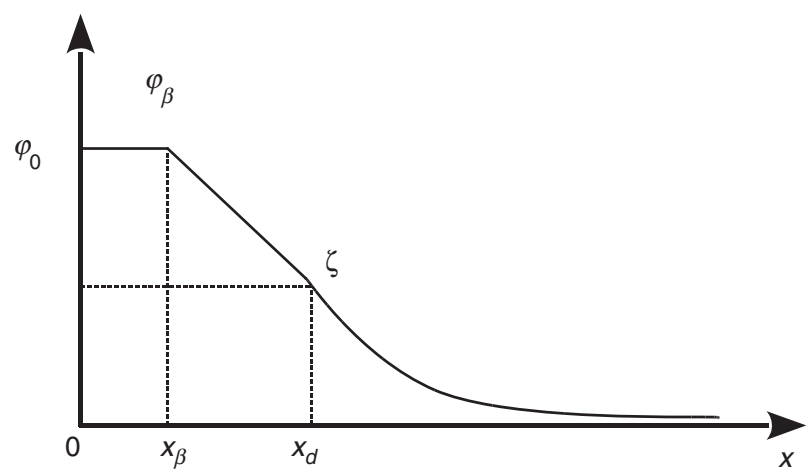

(b)

Fig. 3-Schematic of the calcite/water interface. The calcite surface charge at the 0-plane is zero. Charge at the surface arises from unequal ion complexing at the $\beta$-plane. The diffuse double layer beginning at the distance $x_{d}$ neutralizes the $\beta$-plane charge. Electrostatic profile of the calcite/water interface is shown when the $\beta$-plane is positively charged. Note that the profile is constant between the 0 - and $\beta$-planes because the calcite surface is electrically neutral. The potential at the $d$-plane identifies the $\zeta$-potential.

\begin{tabular}{cccc} 
No. & Reaction & $\log _{10} \mathrm{~K}_{s}$ & Units \\
\hline$S_{1}$ & $>\mathrm{CaH}_{2} \mathrm{O}^{+} \rightleftarrows>\mathrm{CaOH}+\mathrm{H}^{+}$ & -10 & $\mathrm{~mol} / \mathrm{L}$ \\
$S_{2}$ & $>\mathrm{CaH}_{2} \mathrm{O}^{+}+\mathrm{HCO}_{3}^{-} \rightleftarrows>\mathrm{CaHCO}_{3}+\mathrm{H}_{2} \mathrm{O}$ & 2 & $\mathrm{~L} / \mathrm{mol}$ \\
$S_{3}$ & $>\mathrm{CaH}_{2} \mathrm{O}^{+}+\mathrm{CO}_{3}^{2-} \rightleftarrows>\mathrm{CaCO}_{3}^{-}+\mathrm{H}_{2} \mathrm{O}$ & 3 & $\mathrm{~L} / \mathrm{mol}$ \\
$S_{4}$ & $>\mathrm{CO}_{3}^{-}+\mathrm{H}^{+} \rightleftarrows>\mathrm{CO}_{3} \mathrm{H}$ & 8 & $\mathrm{~L} / \mathrm{mol}$ \\
$S_{5}$ & $>\mathrm{CO}_{3}^{-}+\mathrm{Ca}^{2+} \rightleftarrows>\mathrm{CO}_{3} \mathrm{Ca}^{+}$ & 3 & $\mathrm{~L} / \mathrm{mol}$ \\
\hline
\end{tabular}

Table 2-Surface-complexation reactions and corresponding equilibrium constants, $K_{s}(298 \mathrm{~K})$. The $\log _{10} K_{s}$ values are refined from Hiorth et al. (2010) and Heberling et al. (2011).

Overall surface-charge neutrality is imposed, with the $\beta$-plane charge set by the number density of specifically adsorbed ion complexes. The $d$-plane charge density (i.e., that in the diffuse layer) is set by Poisson-Boltzmann (Verwey and Overbeek 1948; Berg 2010), as outlined in Appendix C:

$$
\sigma_{d}=-\frac{\varphi_{d}}{\left|\varphi_{d}\right|} \sqrt{2 \varepsilon R T \sum_{i} C_{i}\left[\exp \left(-\frac{z_{i} F \varphi_{d}}{R T}\right)-1\right]}
$$


where $\varphi_{d}$ is the electrostatic potential at the $d$-plane. For example, if $\varphi_{d}$ is negative, net positive charges must be distributed in the diffuse layer because of a negative electrostatic potential, and vice versa. In our analysis, the $d$-plane is defined as the plane of no-slip so that $\varphi_{d}$ corresponds to the $\zeta$-potential. Finally, Gauss' law relates the potentials $\varphi_{\beta}$ and $\varphi_{d}$ through a constant integral capacitance between the inner and outer Helmholtz planes (Newman and Thomas-Alyea 2004; Berg 2010).

A qualitative electrostatic-potential profile for the calcite/water surface is displayed in Fig. $3 \mathrm{~b}$ for a positively charged $\beta$-plane. The potential remains constant at $\varphi_{0}=\varphi_{\beta}$ between the calcite surface and the inner Helmholtz plane because the 0 -plane surface is neutral. $\varphi(x)$ then falls linearly between the inner and outer Helmholtz planes because that region is assumed devoid of charge. Finally, charge balance is achieved in the diffuse double layer of thickness, $\lambda$, the Debye length given by (Verwey and Overbeek 1948; Newman and Thomas-Alyea 2004; Berg 2010)

$$
\lambda=\sqrt{\frac{\varepsilon R T}{2 F^{2} I}}
$$

where $\varepsilon=\varepsilon_{0} \varepsilon_{r}$ is the dielectric permittivity of water, $\varepsilon_{0}$ is the dielectric permittivity of free space, and $\varepsilon_{r}$ is the relative permittivity or dielectric constant of water. $F$ is Faraday's constant, $R$ is the ideal-gas constant, $I=0.5 \sum_{i} z_{i}^{2} C_{i}$ is the aqueous-solution ionic strength, $z_{i}$ is the valence of dissolved species $i$, and $C_{i}$ is the bulk aqueous molar concentration of that species.

If the $\beta$-plane charge is negative, the potential profile in Fig. $3 \mathrm{~b}$ reverses sign and increases from negative $\varphi_{0}$ at the 0 -plane to zero as $x \rightarrow \infty$. Because many aqueous ions contribute to the $\beta$-plane charge, the $\zeta$-potential $\left(=\varphi_{d}\right)$ of calcite can be either positive or negative depending on solution composition. There is no unique point of zero charge. Many different solution compositions lead to a netneutral $\beta$-plane. Numerical solution of the surface-complexing model is again by Newton iteration, outlined in Appendix C.

According to Eq. 7, when ionic strength increases, $\lambda$ shrinks. At high-enough ionic strength, the diffuse double layer collapses completely. Only when $\lambda$ is larger than approximately $1 \mathrm{~nm}$ (2-4 water layers) does a diffuse double layer exist. Fig. 4 displays the Debye length at ambient temperature as a function of aqueous ionic strength. DLE can only occur if the reservoir-equilibrated brine falls into the upper-left shaded corner of Fig. 4, irrespective of reservoir-rock mineralogy. At least 10-times-diluted seawater is necessary to permit DLE. We assert that DLE is not applicable in most carbonate LSW applications.

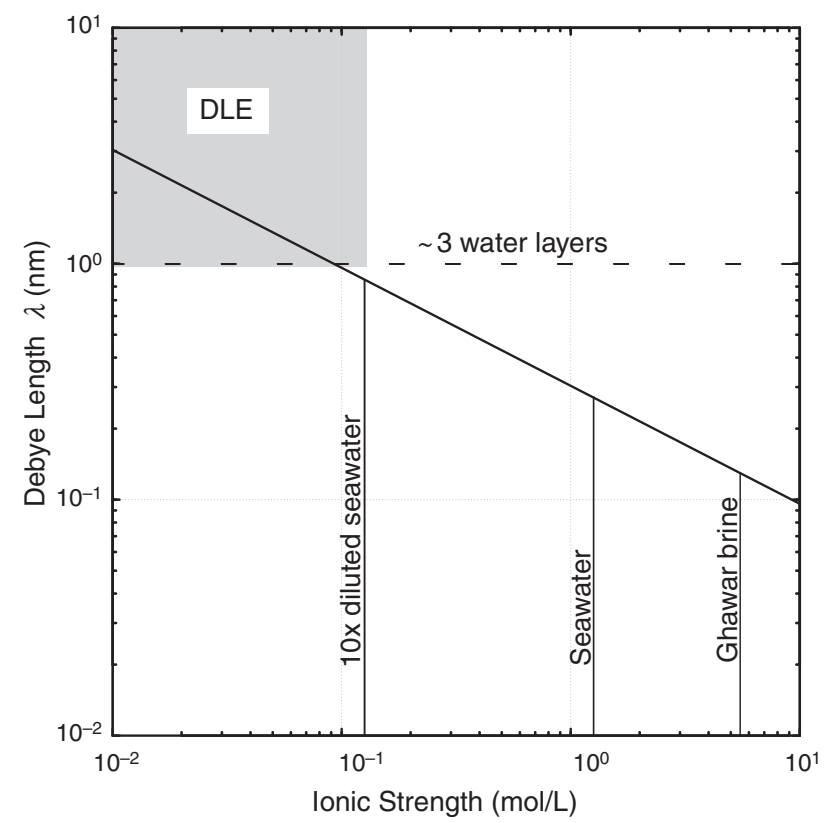

Fig. 4-The Debye length $\lambda=\sqrt{\varepsilon R T / 2 F^{2} I}$ as a function of the brine ionic strength, $I=0.5 \sum_{i} z_{i}^{2} C_{i}$. Only in the shaded region is DLE (or contraction) possible. The dashed line at $\lambda=1 \mathrm{~nm}$ corresponds to approximately three water layers, below which no diffuse double layer exists.

\section{Results and Discussion}

Calcite/Solution Bulk Equilibria. Fig. 5 portrays what happens to injected-brine concentrations during flow through and equilibration with carbonate reservoir rock. Equilibrium-aqueous-species concentrations in calcite rock are graphed as a log-log function of injectedbrine ionic strength. Influent brine is saturated with atmospheric $\mathrm{CO}_{2}(\mathrm{~g})$ at $350 \mathrm{ppm}\left(10^{-3.44} \mathrm{bar}\right)$. This means that injected-brine pH is 5.65. Similarly, reservoir brine is equilibrated with $\mathrm{CO}_{2}(\mathrm{~g})$ at the same partial pressure of $10^{-3.44}$ bar and remains so during flooding. All species in Table 1 are graphed except dissolved $\mathrm{CO}_{2}, \mathrm{CO}_{2}(\mathrm{aq})$, and carbonic acid, $\mathrm{H}_{2} \mathrm{CO}_{3}$, the concentrations of which are fixed and minor [by equilibration with $\mathrm{CO}_{2}$ (oil) and $\mathrm{CO}_{2}(\mathrm{~g})$, where applicable]. Except for very-low ionic-strength injected brines, reservoir ionic strength is identical to that injected. $\mathrm{pH}$ in the reservoir, however, changes substantially to an alkaline value of approximately 8.3. At the highest ionic strengths, the $\mathrm{pH}$ diminishes to approximately 7.9 because of activity-coefficient corrections. All calcite-rock-generated aqueous species are less than $10^{-3} \mathrm{~mol} / \mathrm{L}$, relatively independent of ionic strength, until greater than $\mathrm{I} \approx 1 \mathrm{~mol} / \mathrm{L}$ (near seawater), where there are substantial changes. These again arise from activity-coefficient interactions. Aside, possibly, from the brine-based species $\left(\mathrm{Na}^{+}, \mathrm{NaHCO}_{3}, \mathrm{NaCO}_{3}^{-}\right.$, and $\left.\mathrm{Cl}^{-}\right)$, the calcite-parent ions of calcium, bicarbonate, and carbonate control surface speciation and, hence, the calcite-surface charge (in the $\beta$-plane). Fig. 5 reveals that the flooding brine is not what exists in the reservoir: Ionic strength 
is not altered significantly, but $\mathrm{pH}$ is. Concentrations of the dominant ions known to bind at the calcite/water surface are strongly influenced by rock equilibration. The charge of the calcite/water interface is controlled by rock equilibration and not by injected brine.

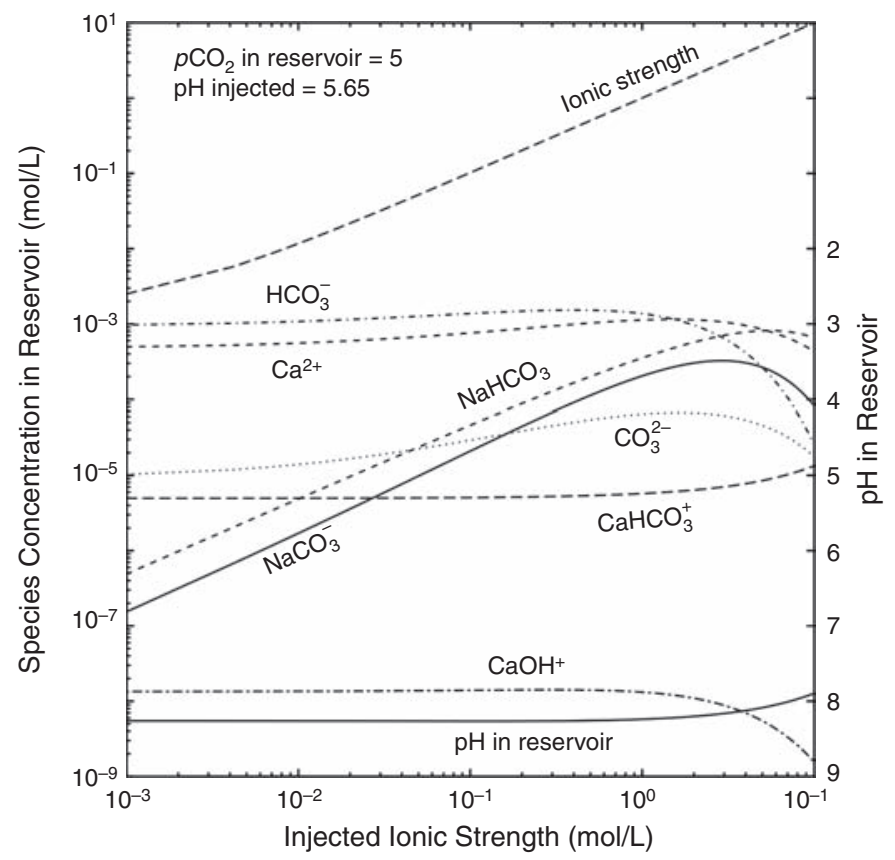

Fig. 5-Reservoir-calcite/water-equilibrium-species concentrations as a function of injected ionic strength (from NaCl) on log-log scales. Injected $\mathrm{NaCl}$ brine is saturated with $\mathrm{CO}_{2}(\mathrm{~g})$ at $10^{-3.44}$ bar, resulting in $10^{-5} \mathrm{~mol} / \mathrm{L}$ of $\mathrm{CO}_{2}(\mathrm{aq})$. The aqueous phase in the calcite rock contains the same amount of dissolved $\mathrm{CO}_{2}$ (i.e., $\mathrm{pCO}_{2}=5$ ).

To emphasize the importance of rock equilibration, Fig. 6 investigates the role of reservoir $\mathrm{CO}_{2}$ either as free gas or dissolved in oil. Fig. 6 graphs aqueous-species concentrations as a function of $p \mathrm{CO}_{2}$ in the reservoir brine on $\log$ - $\log$ scales. Here we display only the dominant ion-complexing species. Injected brine is $1.5 \mathrm{~mol} / \mathrm{L}$ in $\mathrm{NaCl}$ and is saturated with atmospheric $\mathrm{CO}_{2}\left(10^{-3.44}\right.$ bar and $\left.5.65 \mathrm{pH}\right)$. Clearly, ion concentrations change markedly in the presence of reservoir $\mathrm{CO}_{2} . \mathrm{pH}$ falls dramatically, with increasing $\mathrm{CO}_{2}(\mathrm{aq})$ concentration eventually becoming acidic. Both calcium and bicarbonate concentrations increase to more than $10^{-2} \mathrm{~mol} / \mathrm{L}$ with increasing reservoir-brine $\mathrm{CO}_{2}(\mathrm{aq})$ concentration. This can have a major effect on calcite-competitive ion exchange and resulting surface charge. Unfortunately, in-situ $\mathrm{CO}_{2}$ (aq) concentration in most oil reservoirs is not known quantitatively.

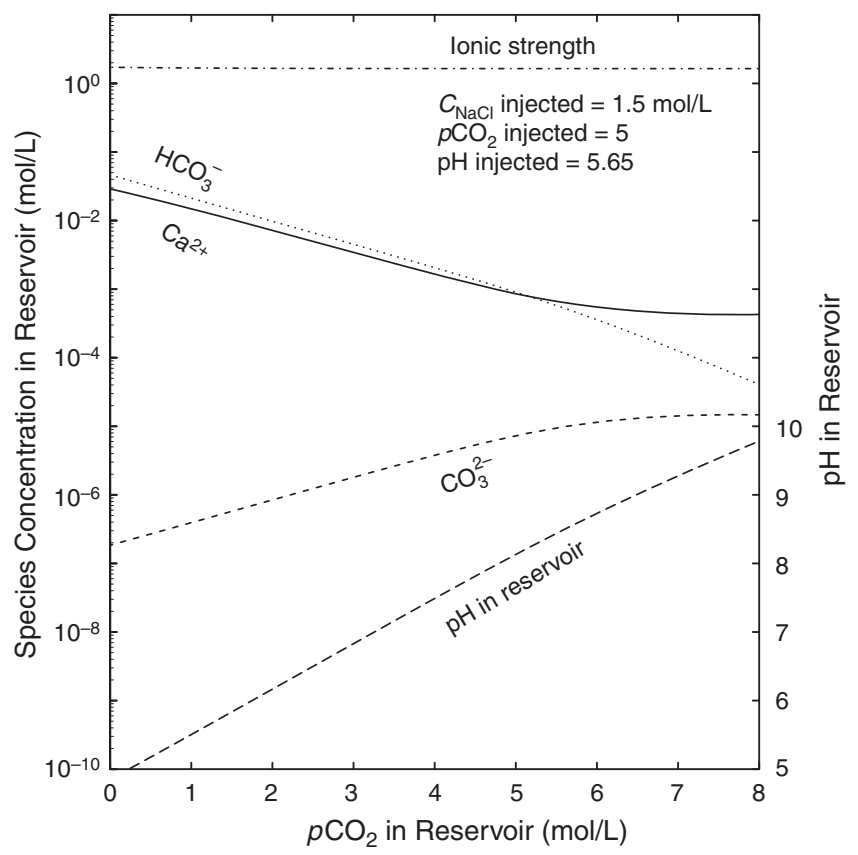

Fig. 6-Reservoir-calcite/water-equilibrium-species concentrations as a function of aqueous $\mathrm{pCO}_{2}$ in the reservoir on log-log scales $\left(\mathrm{CO}_{2}\right.$ concentration increases from right to left). Injected brine at $1.5 \mathrm{~mol} / \mathrm{L} \mathrm{NaCl}$ is saturated with $\mathrm{CO}_{2}(\mathrm{~g}) 10^{-3.44}$ bar, resulting in $10^{-5} \mathrm{~mol} / \mathrm{L}$ of $\mathrm{CO}_{2}(\mathrm{aq}), \mathrm{pH}=5.65$. Henry's constant $=0.034 \mathrm{~mol} / \mathrm{kg} \cdot$ bar at $273 \mathrm{~K}$. 
Fig. 7 explores the possibility of changing the injection-brine $\mathrm{pH}$ to alter alkalinity in the reservoir. Concentrations of the major ionexchanging species are reported for various inlet alkalinities adjusted by dilute sodium hydroxide in $1.5 \mathrm{~mol} / \mathrm{L} \mathrm{NaCl}$ injected brine. Inlet brine contains no dissolved carbon. Up to injected $\mathrm{pH}=11$, the reservoir $\mathrm{pH}$ is unchanged from 8.5. This value appears because of buffering by dissolved carbonate species. Likewise, the ion-exchanging-species concentrations remain constant until a pH value of approximately 11 . Above this inlet $\mathrm{pH}$, reservoir $\mathrm{pH}$ rises, but only to approximately 10 , even with an injected value four orders of magnitude larger. Carbonate buffering is strong and does not permit much alteration of reservoir $\mathrm{pH}$. Again, equilibration of the injected brine with the rock changes the calcium, bicarbonate, and carbonate ion concentrations and, hence, rock-surface chemistry.

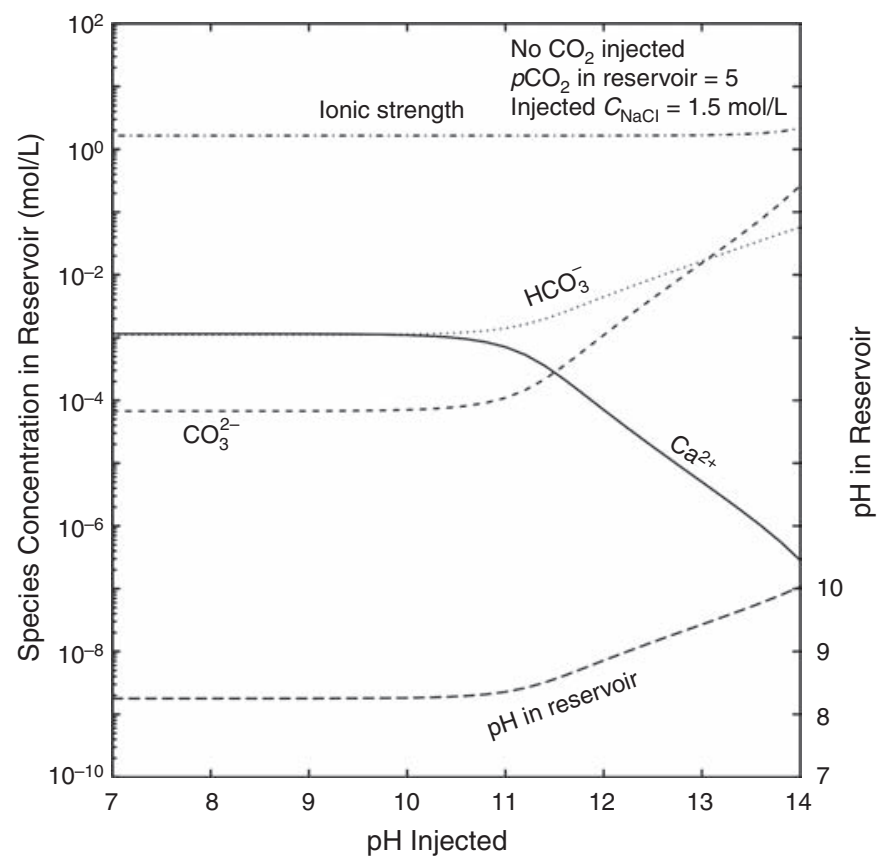

Fig. 7-Reservoir-calcite/water-equilibrium-species concentrations as a function of injected pH (from injected NaOH) on log-log scales. Injected $1.5 \mathrm{~mol} / \mathrm{L} \mathrm{NaCl}$ brine is free of $\mathrm{CO}_{2}$. Concentration of $\mathrm{CO}_{2}(\mathrm{aq})$ in the aqueous phase in contact with calcite rock is kept constant at $p \mathrm{CO}_{2}=5$ in the reservoir.

Carbonate aqueous chemistry is critical to LSW. Injected-brine speciation alters dramatically by reaction equilibration with the rock. Because of buffering and especially because of the presence of reservoir $\mathrm{CO}_{2}, \mathrm{pH}$ values in the reservoir do not deviate much from approximately 8, no matter what $\mathrm{pH}$ is injected. The proposed saponification mechanism for LSW (i.e., activation of surfaceactive soaps) (Buckley and Morrow 2010; Sheng 2014; Myint and Firoozabadi 2015) is not expected to contribute at this low alkalinity. Because surface chemistry of the mineral interface is controlled by aqueous speciation, careful attention must be paid to actual ionic concentrations that evolve in the reservoir. In particular, all ancillary laboratory studies must be performed with rock-equilibrated aqueous solutions at reservoir conditions, including temperature and especially $\mathrm{CO}_{2}$ levels, something that is rarely contemplated. Figs. 5 through 7 provide a glimpse into a large range of possible LSW injection schemes. Many other salinities, particular ions, rock minerals, and temperatures, may be pursued depending on the specific reservoir and LSW process under consideration.

Calcite/Solution Surface Equilibria. Aqueous speciation controls the surface-charge behavior of aqueous-immersed calcite. Because all aqueous ions present have the potential for ion exchange, the surface-chemistry landscape is immense, with no single chargedetermining species. We first consider laboratory studies at low ionic strengths where $\zeta$-potential measurements are possible. This exercise calibrates the SCM and provides physical insight into the calcite-surface structure. We then extend the SCM to brines that might be used in LSW of carbonate reservoirs.

Low Ionic Strength. Most laboratory information on aqueous-calcite-surface behavior is from $\zeta$-potential measurements at relatively low ionic strength, typically less than $0.1 \mathrm{~mol} / \mathrm{L}$ (Somasundaran and Agar 1967; Thompson and Pownall 1989; Van Cappellen et al. 1993; Wolthers et al. 2008; Alotaibi et al. 2011; Heberling et al. 2011; Alshakhs and Kovscek 2015; Alotaibi and Yousef 2015). At high ionic strength, $\zeta$-potentials are small and measurements imprecise. We consider the experimental measurements of Heberling et al. (2011). These authors carefully pre-equilibrate the aqueous solution with calcite mineral and verify the resulting aqueous-solution behavior against separate equilibrium calculations (by use of the PHREEQC code). Because the $\zeta$-potentials are strong functions of ionic strength, Heberling et al. (2011) performed their experiments at approximately constant ionic strength. They also equilibrated the aqueous brine with fixed $\mathrm{CO}_{2}(\mathrm{~g})$ partial pressures, a point emphasized previously. Few $\zeta$-potential studies on calcite pay close attention to the important details that control aqueous speciation and, accordingly, the surface chemistry of the calcite/water interface.

Fig. 8 shows the experimental $\zeta$-potentials of Heberling et al. (2011) as a function of $\mathrm{pH}$ for ionic strengths nominally at $0.1 \mathrm{~mol} / \mathrm{L}$ (open symbols). Three data sets are seen corresponding to equilibration with differing partial pressures of $\mathrm{CO}_{2}$ gas. A larger partial pressure demands larger amounts of $\mathrm{CO}_{2}$ dissolved in the aqueous phase, making the solution more acidic and limiting the range of $\mathrm{pH}$ values at fixed ionic strength. Note that calcite is charged both positively and negatively at each $\mathrm{CO}_{2}$ partial pressure. Further, each partial pressure exhibits a separate point of zero charge, equivalently an isoelectric point, where the $\zeta$-potential crosses zero. $\mathrm{pH}$ alone does not determine calcite-surface charge, as it does for oxide minerals (Stumm and Morgan 1996). 


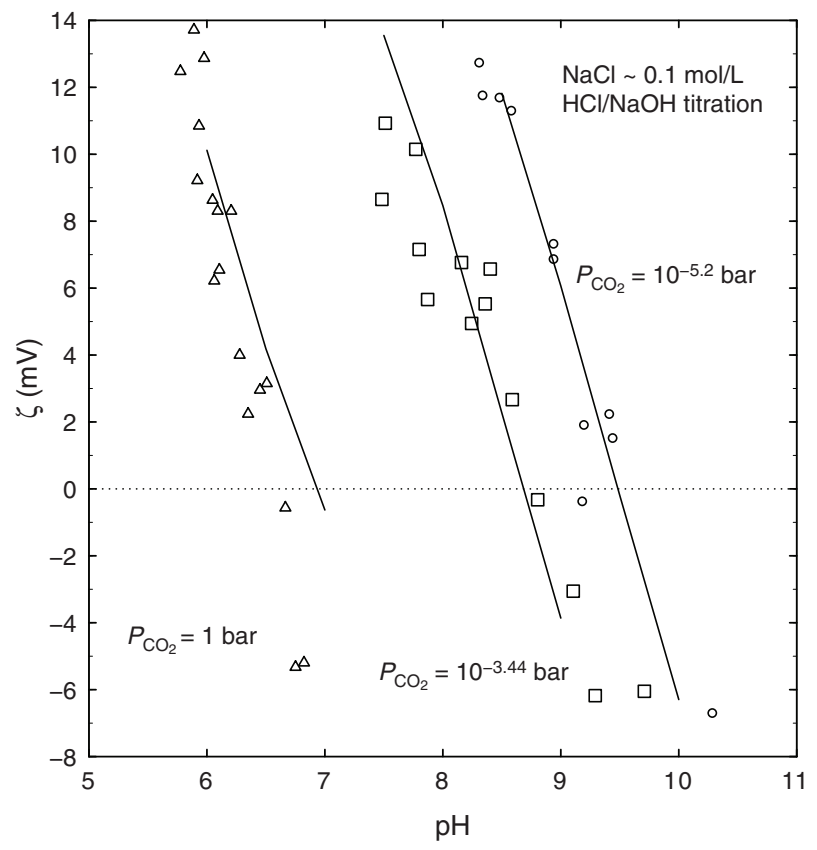

Fig. 8- $\zeta$-potentials of calcite equilibrated with water as a function of $\mathrm{pH}$. Ionic strength is fixed close to $0.1 \mathrm{~mol} / \mathrm{L}$, giving a Debye length of $1 \mathrm{~nm}$. The aqueous-brine solution is equilibrated with $\mathrm{CO}_{2}(\mathrm{~g})$ at partial pressures of 1 bar $\left(\right.$ pure $\left.\mathrm{CO}_{2}\right), 10^{-3.44}$ bar (atmospheric $\mathrm{CO}_{2}$ ), and $10^{-5.2}$ bar. Acid $(\mathrm{HCl})$ and base $(\mathrm{NaOH})$ adjust the solution pH at each fixed $\mathrm{CO}_{2}(\mathrm{~g})$ partial pressure so that ionic strength does not deviate much from $0.1 \mathrm{~mol} / \mathrm{L}$. Experimental and computational results for this set of experiments have the lowest accuracy because it is difficult both experimentally and computationally to keep ionic strength close to $0.1 \mathrm{M}$.

The lines in Fig. 8 correspond to our surface-complex model. The surface-complexing equilibrium constants, $K_{S_{i}}$, are first estimated from literature and then eye-fit to the data in Fig. 8. We do not attempt a best-minimum fit. The resulting preliminary values for $K_{S_{i}}$ are listed in Table 2. These values are subject to refinement when new experimental data are available. The remaining parameter values are given in Table 3 and Appendix C.

\begin{tabular}{lcc} 
Parameter & Value & Units \\
\hline Dielectric constant between $\beta$ - and $d$-planes $\left(\varepsilon_{r}\right)$ & 15 & - \\
Average dielectric constant in diffuse layer $\left(\varepsilon_{r_{\text {avg }}}\right)$ & $50^{*}$ & - \\
Integral capacitance between $\beta$ - and $d$-planes & 13 & $\mu \mathrm{F} / \mathrm{cm}^{2}$ \\
\hline${ }^{*}$ Rounded average of 78.3 and 15. & & \\
\hline
\end{tabular}

Table 3-SCM parameters.

The SCM is enlisted in Fig. 9 to illustrate why the calcite $\beta$-plane charge changes sign from positive to negative and why it does so at different $\mathrm{pH}$ values upon different saturations of aqueous-dissolved $\mathrm{CO}_{2}$. The left abscissa gives the $\beta$-plane surface concentrations, $\Gamma_{i}$, of four ion complexes in Table 2 as a function of $\mathrm{pH}$ at a fixed $\mathrm{P}_{\mathrm{CO}_{2}}$ of $10^{-3.44}$ bar corresponding to the $\mathrm{pH}$ value range of 8 to 9 in Fig. 8. The fifth species, $>\mathrm{CaOH}$ in Table 2, is not displayed because its surface density is one order of magnitude smaller and is constant over this $\mathrm{pH}$ range. Surface-complex densities reported on the left abscissa are relative to the maximum anion (or cation) exchange capacity $\left(\Gamma_{\max }=5 \mathrm{~nm}^{-2}\right.$ corresponding to $\left.80 \mu \mathrm{C} / \mathrm{cm}^{2}\right)$. The net-charge density in the $\beta$-plane is shown as a solid line and reported on the right abscissa in units of $\mu \mathrm{C} / \mathrm{cm}^{2}$. Ordinals in parentheses labeling each surface complex correspond to the valence of that complex in the $\beta$-plane. For example, the divalent $\mathrm{CO}_{3}^{2-}$ ion in the surface species $>\mathrm{CaCO}_{3}^{-}$exhibits a valence of $(-2)$ in the $\beta$-plane.

The zero point of charge in Fig. 9 is $\mathrm{pH}=8.75$, as in Fig. 8. Surprisingly, charge densities of all surface complexes at the inner Helmholtz plane are less than 10 to $20 \%$ of the maximum possible. This means that approximately $30 \%$ of each ion-exchange capacity is surface-complexed (the remaining $70 \%$ is uncomplexed). The two main surface complexes are $>\mathrm{CaH}_{2} \mathrm{O}^{+}$and $>\mathrm{CO}_{3} \mathrm{H}$, but they do not change surface density in the $\mathrm{pH}$ range of Fig. 9. Minority complexes, $>\mathrm{CaCO}_{3}^{-}$and $>\mathrm{CO}_{3} \mathrm{Ca}^{+}$, change surface density slightly with $\mathrm{pH}$. Because each of these complexes has a valence magnitude of 2 , however, the small change with pH is enough to yield an isoelectric point. We find that surface-charge behavior of the calcite/water interface at ionic strengths of approximately 0.1 mol/L is complicated and subtle. Except for the surface species $>\mathrm{CaOH}$, all remaining complexes contribute substantially to the inner Helmholtz-plane charge. Calculations at the other two $\mathrm{CO}_{2}(\mathrm{~g})$ partial pressures in Fig. 8 indicate similar subtle surface-charge behavior. This result depends strongly on the particular set of surface species chosen and on their corresponding values of surface-equilibrium constants. Additional data are needed to draw stronger conclusions.

High Ionic Strength. The main distinction between charge characterization of the calcite/water interface in laboratory experiments and that at reservoir conditions is the much higher ionic strength. Fig. 10 reports SCM predictions (right abscissa) of $\zeta$-potentials (upper solid line) and $\beta$-plane charge densities $\sigma_{\beta}$ (lower solid line), as a function of injected-brine $\mathrm{pH}$ at $1.5 \mathrm{~mol} / \mathrm{L}$ ionic strength (seawater) in a reservoir exposed to atmospheric $\mathrm{CO}_{2}(\mathrm{~g})$. Bulk aqueous-species concentrations appear on the left abscissa. For injected pH values less than approximately 11.5 , there is a positive $\beta$-plane charge. High ionic strengths do not neutralize the $\beta$-plane and, hence, the surface. At an ionic strength of $1.5 \mathrm{~mol} / \mathrm{L}$, the Debye length in Fig. 4 is approximately $0.3 \mathrm{~nm}$; therefore, the diffuse double layer 
completely collapses directly onto the $d$-plane. Nevertheless, below injected pH values of 11 , SCM demonstrates a small positive $\zeta$-potential of approximately $1 \mathrm{mV}$, barely measurable by available laboratory techniques. Small but finite values of $\zeta$-potential remain at high ionic strength because sodium ions scavenge carbonate and bicarbonate ions (Reactions 9 and 10 in Table 1), thereby raising the charge density in the $\beta$-plane. This observation accentuates that equilibrium-solution speciation controls surface charge.

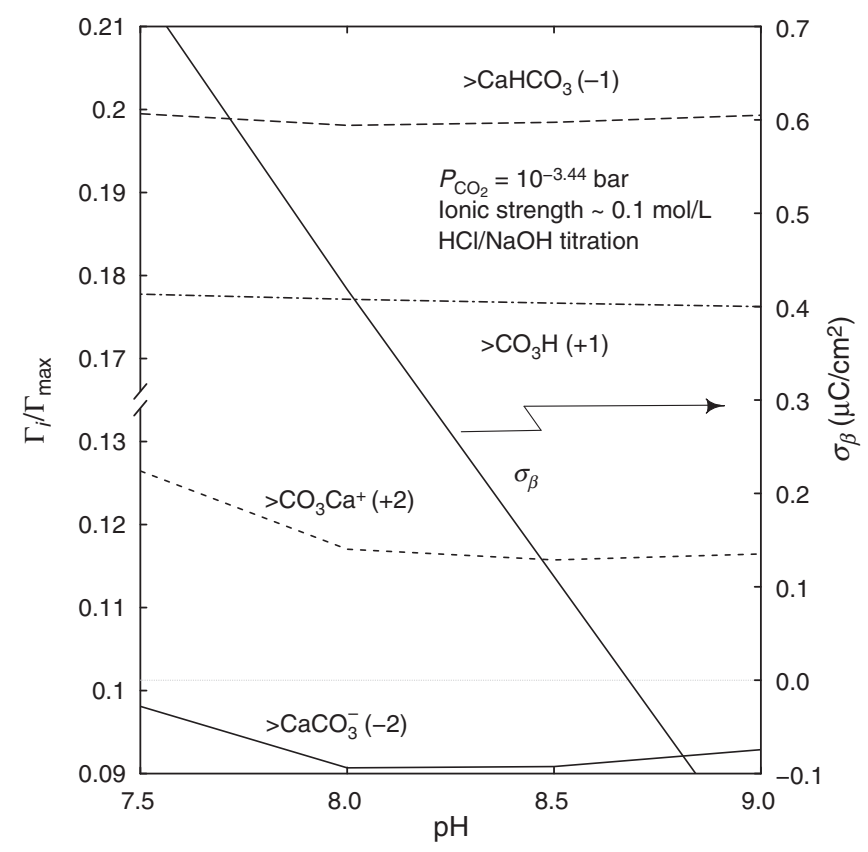

Fig. 9-Ion-complex-surface densities normalized by the ion-exchange capacity of $5 \mathrm{~nm}^{-2}$ as a function of $\mathrm{pH}$ at $P_{\mathrm{CO}_{2}}=10^{-3.44}$ bar (see Fig. 5). The $\beta$-plane surface-charge density is shown on the right abscissa. The point of zero charge is $\mathrm{pH}=8.75$, as in Fig. 8 . Numbers in the parentheses following each surface-complex indicate the valence of this species in the $\beta$-plane.

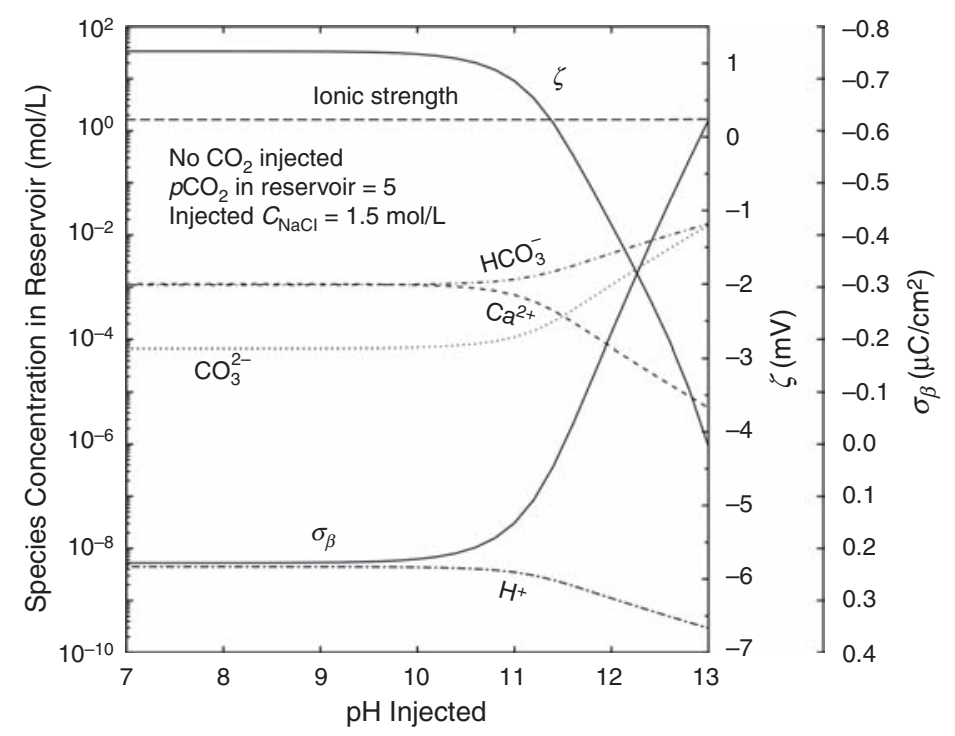

Fig. 10-Aqueous speciation, $\zeta$-potential, and $\beta$-plane surface-charge density as a function of pH at $1.5 \mathrm{~mol} / \mathrm{L}$ ionic strength (close to seawater). The $\zeta$-potential (upper solid line that belongs to right abscissa) and the $\beta$-plane surface-charge density $\sigma_{\beta}$ (lower solid line that belongs to far-right abscissa) are shown.

At $\mathrm{pH}$ values greater than 11 , the $\beta$-plane charge turns increasingly negative because all surface-complex reactions shift by mass action toward ever-more-negative charge. The collapsed diffuse-double-layer electrostatic potential $\varphi_{d}(=\zeta)$ follows suit. Aqueous speciation in the reservoir brine controls the surface charge. We assert that carbonate rock/water surfaces remain charged and participate in ion-exchange reactions even at high ionic strengths relevant to LSW (Möller and Werr 1972). However, DLE is no longer operative.

The observation that ion exchange on calcite is active at high ionic strength is crucial to the LSW of carbonate reservoirs. One proposed mechanism of improving waterflood performance is to displace asphaltic carboxylates tightly bound to the rock surface by ion complexing and bridging by tailored solution ions (Lager et al. 2006, 2007, 2008a, b; Strand et al. 2006; Zhang and Austad 2006; Zhang et al. 2007b; Sorbie and Collins 2010; Zahid et al. 2012; Austad et al. 2015; Puntervold et al. 2015; Qiao et al. 2016). MIE is strongly coupled to rock/brine-surface chemistry. Ion-exchange oil release appears feasible in carbonate rocks even at high salinity and deserves more experimental attention. 
Successful design of LSW in carbonate reservoirs presents severe challenges because rock/water reactions and highly concentrated brines cloud the understanding of COBR surface chemistries. Calcite rapidly equilibrates with aqueous solution within very short distances, even at high flow rates in fractures. The result is that injected-brine concentrations are not those found in the reservoir. In particular, injected-brine $\mathrm{pH}$ is altered substantially because of buffering by dissolving rock. Depending on the $\mathrm{CO}_{2}$ content of the reservoir, it is difficult to achieve alkalinities much different from $\mathrm{pH} \approx 8.3$ upon equilibration with calcite. Rock/water-surface chemistry is controlled by aqueous speciation present in the reservoir and not that injected. These findings are not changed when more-realistic brines are injected other than sodium chloride (illustrated in Figs. 5 through 7). We caution that all pertinent laboratory experiments should be performed with aqueous solutions that are pre-equilibrated with the rock and have $\mathrm{CO}_{2}(\mathrm{aq})$ levels carefully adjusted to those anticipated in the field.

Surface-charge behavior is important to the success (or failure) of LSW. It is controlled by reservoir aqueous composition. Our preliminary effort to understand the electrical behavior of the calcite/water interface successfully predicts measured $\zeta$-potentials and confirms the critical role of aqueous speciation. This exercise permits estimation of surface charge under more-realistic LSW conditions. We find that because the calcite-surface lattice is neutral, surface charge of the calcite/water interface is at the inner Helmholtz plane. Because of ion-exchange reactions, surface charge may be positive or negative depending delicately on aqueous speciation in the reservoir. At brine ionic strengths beyond approximately 0.1 molar $(\approx 5,000 \mathrm{ppm}$ of total dissolved salt, based on $\mathrm{NaCl})$, the diffuse double layer collapses completely onto the outer Helmholtz plane. There is no "diffuseness" to the diffuse double layer. This does not mean that the calcite surface is overall neutral; ion exchange remains active and is quite important to LSW. Future work will focus on the important role of crude oil and MIE in LSW.

Our findings draw inferences concerning several proposed LSW oil-recovery mechanisms. Because of the high brine concentrations in carbonate reservoirs, diffuse DLE is precluded. Likewise, fines release is not possible for the same reason. In addition, carbonate rocks contain minimal or no clays. Because aqueous equilibration with carbonate rock is essentially instantaneous, the proposed dissolution LSW mechanism is not possible. Within a short kinetically controlled equilibration distance, rock no longer dissolves. Calculations of aqueous speciation under reservoir conditions suggest a $\mathrm{pH}$ that is too low for significant activation of oil-soluble acids into effective surfactants. Thus, the saponification mechanism for LSW is doubtful even if highly alkaline brine is injected. However, ion exchange remains active on calcite surfaces at high ionic strengths, suggesting that ligand-ion-exchange oil release is feasible in carbonate rocks.

We stress the importance of rock/brine equilibration under reservoir conditions when considering LSW. A simple but effective formulation is presented for scoping calculations of LSW performance.

\section{Nomenclature}

$a_{i}^{\circ}=$ first Truesdell-Jones equation ion-specific parameter, length

$a_{i}^{e}=$ activity of species $i$, where upper index $e$ denotes equilibrium state when specified, mol/L

$a_{V}=$ surface area per unit volume, length ${ }^{-1}$

$A=$ first Davies equation parameter, $\sqrt{\mathrm{mol} / \mathrm{L}}$

$b_{i}=$ second Truesdell-Jones equation ion-specific parameter, $\mathrm{L} / \mathrm{mol}$

$B=$ second Davies equation parameter, $\sqrt{\mathrm{mol} / \mathrm{L}} / \mathrm{nm}$

$\bar{C}_{2}=$ constant integral capacitance between the inner and outer Helmholtz planes

$C_{i}=i$ th species concentration, where bottom tilde denotes vector of concentrations, $\mathrm{mol} / \mathrm{L}$

$\tilde{C_{i L}}=i$ th species concentration at position $L, \mathrm{~mol} / \mathrm{L}$

$D=$ aqueous-salt diffusion coefficient, length ${ }^{2} /$ time $^{2}$

$D a=$ Damköhler number: $D a \equiv t_{\text {res }} / t_{\text {dis }}$, unitless

$D_{g}=$ grain size, length

$f=$ vector of equations in the last column of Table B-1

$F=$ Faraday's constant, charge/mol

$I=$ ionic strength, $\mathrm{mol} / \mathrm{L}$

$k_{m}=$ convective mass-transfer coefficient, length/time

$k_{r x n}=$ intrinsic dissolution rate constant, length/time

$K_{j}=$ equilibrium constant of $j$ th reaction, units depend on reaction

$K_{S i}=$ equilibrium constant of $i$ th surface reaction, units depend on reaction

$K_{S P}=$ solubility product of calcium carbonate, $\mathrm{mol}^{2} / \mathrm{L}^{2}$

$L=$ characteristic length, length

$P e=$ Péclet number, $u \delta / D$, unitless

$r_{A}=$ calcium carbonate dissolution rate in water, mol/length/time

$R=$ ideal gas constant, volume $\times$ pressure/(temperature $\times$ mol)

$S_{i}=i$ th surface reaction, unitless

$t_{\text {dis }}=$ characteristic rock-dissolution time, time

$t_{m}=$ characteristic mass-transport time, time

$t_{\text {res }}=$ residence time in the porous medium, time

$t_{r x n}=$ characteristic reaction time for calcium carbonate rock, time

$T=$ absolute temperature, $\mathrm{K}$

$u=$ frontal advance rate, length/time

$v=$ characteristic velocity, length/time

$z_{i}=$ valence of $i$ th species, unitless

$\gamma_{\mathrm{H}^{+}}=$activity coefficient of hydronium ion in solution, unitless

$\gamma_{i}=$ dilute-solution activity coefficient of species $i$, unitless

$\Gamma=$ ion-exchange capacity, where index denotes the state, unitless

$\delta=$ gap/fracture thickness, length

$\varepsilon=$ dielectric permittivity of water, Farads $/ \mathrm{m}$

$\varepsilon_{0}=$ dielectric permittivity of free space, Farads $/ \mathrm{m}$

$\varepsilon_{r}=$ relative permittivity of water, unitless

$\varepsilon_{\text {ravg }}=$ average dielectric constant in diffuse layer 
$\zeta=$ zeta potential, energy/charge

$\kappa=$ scaling constant, length $=$ time $\times$ concentration

$\lambda=$ Debye length $\sqrt{\frac{\varepsilon R T}{2 F^{2} I}}$, length

$\mu_{i}^{\circ / e}=$ Chemical potential of species $I$; symbol ${ }^{\circ}$ denotes the standard-state Gibbs free energy of aqueous species $i$, while $e$ indicates chemical potential at equilibrium, energy

$\nu_{i j}=$ stoichiometric coefficient of species $i$ in $j$ reaction, unitless

$\xi_{j}=$ extent of the $j$ th reaction, where bottom tilde denotes vector of extents, mol/L

$\sigma_{0 / \beta / d}=$ net surface charge density, where $0, \beta$, and $d$ denote different planes, charge/area

$\varphi_{0 / \beta / d}=$ electrostatic potential at $0-, \beta$-, and $d$-planes, energy/charge

\section{Other Notations}

$>\mathrm{CaHCO}_{3}=$ notation used to denote surface species, where $>$ denotes mineral surface

$\mathrm{CO}_{2}(\mathrm{aq})=$ denotes aqueous $\mathrm{CO}_{2}(\mathrm{~g})$

$\mathrm{CO}_{2}(\mathrm{~g})=$ denotes $\mathrm{CO}_{2}$ in gas phase

$\mathrm{CO}_{2}($ oil $)=$ denotes $\mathrm{CO}_{2}(\mathrm{~g})$ dissolved in oil phase

$P_{\mathrm{CO}_{2}}=$ partial pressure of $\mathrm{CO}_{2}(\mathrm{~g})$

$p \mathrm{CO}_{2}=-\log _{10}\left[\mathrm{CO}_{2}(\mathrm{aq})\right]$

$\mathrm{pH}=-\log _{10}\left[a_{\mathrm{H}+}\right]$

\section{Acknowledgments}

Author Clayton J. Radke acknowledges the Ali I. Al-Naimi Petroleum Engineering Research Center (ANPERC) of King Abdullah University of Science and Technology (KAUST) for hosting a sabbatical visit and Jagan Mahadevan for introducing this problem. Funding for this project has been provided by KAUST through ANPERC.

\section{References}

Al-Shalabi, E. W., Sepehrnoori, K., and Pope, G. 2014. Geochemical Interpretation of Low Salinity Water Injection in Carbonate Oil Reservoirs. Presented at the SPE Improved Oil Recovery Symposium, Tulsa, 12-16 April. SPE-169101-MS. https://doi.org/10.2118/169101-MS.

Alotaibi, M. B. and Yousef, A. A. 2015. The Impact of Dissolved Species on the Reservoir Fluids and Rock Interactions in Carbonates. Presented at the SPE Saudi Arabia Section Annual Technical Symposium and Exhibition, Al-Khobar, Saudi Arabia, 21-23 April. SPE-177983-MS. https://doi.org/ 10.2118/177983-MS.

Alotaibi, M. B., Nasr-El-Din, H. A., and Fletcher, J. 2011. Electrokinetics of Limestone and Dolomite Rock Particles. SPE Res Eval \& Eng 14 (5): 594-603. SPE-148701-PA. https://doi.org/10.2118/148701-PA.

Alshakhs, M. J. and Kovscek, A. R. 2015. An Experimental Study of the Impact of Injection Water Composition on Oil Recovery from Carbonate Rocks. Presented at SPE Annual Technical Conference and Exhibition, Houston, 28-30 September. SPE-175147-MS. https://doi.org/10.2118/175147-MS.

Arvidson, R. S., Ertan, I. E., Amonette, J. E. et al. 2003. Variation in Calcite Dissolution Rates: A Fundamental Problem? Geochim. Cosmochim. Ac. 67 (9):1623-1634, 2003. https://doi.org/10.1016/S0016-7037(02)01177-8.

Austad, T., Shariatpanahi, S. F., Strand, S. et al. 2015. Low Salinity EOR Effects in Limestone Reservoir Cores Containing Anhydrite: A Discussion of the Chemical Mechanism. Energ. Fuel. 29 (11): 6903-6911. https://doi.org/10.1021/acs.energyfuels.5b01099.

Berg, J. C. 2010. An Introduction to Interfaces \& Colloids: The Bridge to Nanoscience. Singapore: World Scientific.

Bird, R. B., Stewart, W. E., and Lightfoot, E. N. 2007. Transport Phenomena, second edition. New York City: Wiley.

Brady, P. V., Morrow, N. R., Fogden, A. et al. 2015. Electrostatics and the Low Salinity Effect in Sandstone Reservoirs. Energ. Fuel. 29 (2): 666-677. https://doi.org/10.1021/ef502474a.

Buckley, J. S. and Morrow, N. R. 2010. Improved Oil Recovery by Low Salinity Waterflooding: A Mechanistic Review. Oral presentation given at the 11th International Symposium on Evaluation of Wettability and Its Effect on Oil Recovery, Calgary, 6-9 September.

Chandrasekhar, S. and Mohanty, K. K. 2013. Wettability Alteration with Brine Composition in High Temperature Carbonate Reservoirs. Presented at the SPE Annual Technical Conference and Exhibition, New Orleans, 30 September-2 October. SPE-166280-MS. https://doi.org/10.2118/166280-MS.

Charlton, S. R. and Parkhurst, D. L. 2011. Modules Based On the Geochemical Model PHREEQC for Use in Scripting and Programming Languages. Comput. Geosci. 37 (10): 1653-1663. https://doi.org/10.1016/j.cageo.2011.02.005.

Chou, L., Garrels, R. M., and Wollast, R. 1989. Comparative Study of the Kinetics and Mechanisms of Dissolution of Carbonate Minerals. Chem. Geol. 78 (3-4): 269-282. https://doi.org/10.1016/0009-2541(89)90063-6.

Cubillas, P., Köhler, S., Prieto, M. et al. 2005. Experimental Determination of the Dissolution Rates of Calcite, Aragonite, and Bivalves. Chem. Geol. 216 (1-2): 59-77. https://doi.org/10.1016/j.chemgeo.2004.11.009.

Davies, C. W. 1962. Ion Association. Oxford, UK: Butterworths.

Davis, J., James, R., and Leckie, J. 1978. Surface Ionization and Complexation at the Oxide/Water Interface: I. Computation of Electrical Double Layer Properties in Simple Electrolytes. J. Colloid Interf. Sci. 63 (3): 480-499. https://doi.org/10.1016/S0021-9797(78)80009-5.

Davis, J. A. and Kent, D. B. 1990. Surface Complexation Modeling in Aqueous Geochemistry. Rev. Mineral. Geochem. 23 (1): 177-260.

Dzombak, D. A. and Morel, F. M. M. 1990. Surface Complexation Modeling: Hydrous Ferric Oxide. Hoboken, New Jersey: John Wiley \& Sons.

Eisenlohr, L., Meteva, K., Gabrovšek, F. et al. 1999. The Inhibiting Action of Intrinsic Impurities in Natural Calcium Carbonate Minerals to Their Dissolution Kinetics in Aqueous $\mathrm{H}_{2} \mathrm{OCO}_{2}$ Solutions. Geochim. Cosmochim. Ac. 63 (78): 989-1001. https://doi.org/10.1016/S0016-7037(98)00301-9.

Fathi, S. J., Austad, T., and Strand, S. 2010. "Smart Water" as a Wettability Modifier in Chalk: The Effect of Salinity and Ionic Composition. Energ. Fuel. 24 (4): 2514-2519. https://doi.org/10.1021/ef901304m.

Felder, R. M., Rousseau, R. W., and Bullard, L. G. 2015. Elementary Principles of Chemical Processes, fourth edition. New York City: Wiley.

Fenter, P., Geissbühler, P., Dimasi, E. et al. 2000. Surface Speciation of Calcite Observed In Situ by High-Resolution X-Ray Reflectivity. Geochim. Cosmochim. Ac. 64 (7): 1221-1228. https://doi.org/10.1016/S0016-7037(99)00403-2.

Folk, R. L. 1959. Practical Petrographic Classification of Limestones. AAPG Bull. 43 (1): 1-38. https://doi.org/10.1306/0BDA5C36-16BD-11D7$8645000102 \mathrm{C} 1865 \mathrm{D}$.

Folk, R. L. 1962. Spectral Subdivision of Limestone Types. In Memoir 1: Classification of Carbonate Rocks - A Symposium, AAPG Special Volumes, ed. W. E. Ham, 62-84. Tulsa: American Association of Petroleum Geologists. 
Geissbühler, P., Fenter, P., DiMasi, E. et al. 2004. Three-Dimensional Structure of the Calcite-Water Interface by Surface X-Ray Scattering. Surf. Sci. 573 (2): 191-203. https://doi.org/10.1016/j.susc.2004.09.036.

Grahame, D. C. 1947. The Electrical Double Layer and the Theory of Electrocapillarity. Chem. Rev. 41 (3): 441-501. https://doi.org/10.1021/ cr60130a002.

Heberling, F., Trainor, T. P., Lützenkirchen, J. et al. 2011. Structure and Reactivity of the Calcite-Water Interface. J. Colloid Interf. Sci. 354 (2): 843-857. https://doi.org/10.1016/j.jcis.2010.10.047.

Hiemstra, T. and Riemsdijk, W. H. 1996. A Surface Structural Approach to Ion Adsorption: The Charge Distribution (CD) Model. J. Colloid Interf. Sci. 179 (2): 488-508. https://doi.org/10.1006/jcis.1996.0242.

Hiorth, A., Cathles, L. M., and Madland, M. V. 2010. The Impact of Pore Water Chemistry on Carbonate Surface Charge and Oil Wettability. Transport Porous Med. 85 (1): 1-21. https://doi.org/10.1007/s11242-010-9543-6.

Jadhunandan, P. P. and Morrow, N. R. 1995. Effect of Wettability on Waterflood Recovery for Crude-Oil/Brine/Rock Systems. SPE Res Eval \& Eng 10 (1): 40-46. SPE-22597-PA. https://doi.org/10.2118/22597-PA.

Kerisit, S. and Parker, S. C. 2004. Free Energy of Adsorption of Water and Calcium on the [1014] Calcite Surface. Chem. Commun. 1: 52-53. https:// doi.org/10.1039/b311928a.

Kim, S. and Santamarina, J. C. 2016. Geometry-Coupled Reactive Fluid Transport at the Fracture Scale: Application to $\mathrm{CO}_{2} \mathrm{Geologic}_{\text {Storage. Geofluids }}$ 16 (2): 329-341. https://doi.org/10.1111/gfl.12152.

Lager, A., Webb, K. J., and Black, C. J. J. 2007. Impact of Brine Chemistry on Oil Recovery Experiments. Oral presentation given at IOR 2007 - the 14th European Symposium on Improved Oil Recovery, Cairo, 2-224 April.

Lager, A., Webb, K. J., Black, C. J. J. et al. 2006. Low Salinity Oil Recovery - An Experimental Investigation. Oral presentation of paper SCA2006-36 given at the International Symposium of the Society of Core Analysts, Trondheim, Norway, 12-16 September.

Lager, A., Webb, K. J., Black, C. J. J. et al. 2008a. Low Salinity Oil Recovery - An Experimental Investigation. Petrophysics 49 (1): 28-35. SPWLA2008-v49n1a2.

Lager, A., Webb, K. J., Collins, R. I. et al. 2008b. LoSal Enhanced Oil Recovery: Evidence of Enhanced Oil Recovery at the Reservoir Scale. Presented at the SPE Symposium on Improved Oil Recovery, Tulsa, 19-23 April. SPE-113976-MS. https://doi.org/10.2118/113976-MS.

Lasaga, A. C. and Luttge, A. 2001. Variation of Crystal Dissolution Rate Based on a Dissolution Stepwave Model. Science 291 (5512): $2400-2404$. https://doi.org/10.1126/science.1058173.

Lasaga, A. C., Soler, J. M., Ganor, J. et al. 1994. Chemical Weathering Rate Laws and Global Geochemical Cycles. Geochim. Cosmochim. Ac. 58 (10): 2361-2386. https://doi.org/10.1016/0016-7037(94)90016-7.

Lashkarbolooki, M., Riazi, M., Hajibagheri, F. et al. 2016. Low Salinity Injection into Asphaltenic-Carbonate Oil Reservoir, Mechanistical Study. J. Mol. Liq. 216 (April): 377-386. https://doi.org/10.1016/j.molliq.2016.01.051.

Levine, S., Mingins, J., and Bell, G. M. 1967. The Discrete-Ion Effect in Ionic Double-Layer Theory. J. Electroanal. Chem. 13 (3): $280-329$. https:// doi.org/10.1016/0022-0728(67)80125-6.

Lu, P., Wang, Q., Chen, T. et al. 2016. A New Approach for Modeling Scale Formation during Water Injection into Carbonate Reservoirs. Presented at the SPE Kingdom of Saudi Arabia Annual Technical Symposium and Exhibition, Dammam, Saudi Arabia, 25-28 April. SPE-182762-MS. https:// doi.org/10.2118/182762-MS.

Lucia, F. J. 2007. Carbonate Reservoir Characterization: An Integrated Approach, second edition. Berlin: Springer Berlin Heidelberg

MATLAB, version 8.6 (R2015b). 2015. Natick, Massachusetts: The MathWorks, Inc.

Möller, P. and Sastri, C. S. 1974. Estimation of the Number of Surface Layers of Calcite Involved in Ca $-{ }^{45}$ Ca Isotopic Exchange with Solution. Int. J. Res. Phys. Chem. Chem. Phys. 89 (1-4):80-87. https://doi.org/10.1524/zpch.1974.89.1-4.080.

Möller, P. and Werr, G. 1972. Influence of Anions on $\mathrm{Ca}^{2+}-\mathrm{Mg}^{2+}$ Surface Exchange Process on Calcite in Artificial Sea Water. Radiochim. Ac. 18 (3): 144-147. https://doi.org/10.1524/ract.1972.18.3.144.

Morrow, N. R. and Buckley, J. 2013. Improved Oil Recovery by Low-Salinity Waterflooding. J Pet Technol 63 (5): 106-112. SPE-129421-JPT. https:// doi.org/10.2118/129421-JPT.

Morse, J. W. and Arvidson, R. S. 2002. The Dissolution Kinetics of Major Sedimentary Carbonate Minerals. Earth Sci. Rev. 58 (1-2): 51-84. https:// doi.org/10.1016/S0012-8252(01)00083-6.

Mugele, F., Siretanu, I., Kumar, N. et al. 2016. Insights From Ion Adsorption and Contact-Angle Alteration at Mineral Surfaces for Low-Salinity Waterflooding. SPE J. 21 (4): 1204-1213. SPE-169143-PA. https://doi.org/10.2118/169143-PA.

Myint, P. C. and Firoozabadi, A. 2015. Thin Liquid Films in Improved Oil Recovery from Low-Salinity Brine. Curr. Opin. Colloid Interf. Sci. 20 (2): 105-114. https://doi.org/10.1016/j.cocis.2015.03.002.

Nasralla, R. A. and Nasr-El-Din, H. A. 2012. Double-Layer Expansion: Is It a Primary Mechanism of Improved Oil Recovery by Low-Salinity Waterflooding? Presented at the SPE Improved Oil Recovery Symposium, Tulsa, 14-18 April. SPE-154334-MS. https://doi.org/10.2118/154334-MS.

Newman, J. and Thomas-Alyea, K. 2004. Electrochemical Systems, third edition. Hoboken, New Jersey: John Wiley \& Sons.

Nystrom, R. 2001. The Influence of $\mathrm{Na}+, \mathrm{Ca} 2+, \mathrm{Ba} 2+$, and La3 + on the $\zeta$ Potential and the Yield Stress of Calcite Dispersions. J. Colloid Interf. Sci. 242 (1): 259-263. https://doi.org/10.1006/jcis.2001.7766.

Palandri, J. L. and Kharaka, Y. K. 2004. A Compilation of Rate Parameters of Water-Mineral Interaction Kinetics for Application to Geochemical Modeling. US Geological Survey Open File Report of 2004-1068, National Energy Technology Laboratory, US Department of Energy, Menlo Park, California, March 2004.

Parkhurst, D. and Apello, C. 2014. Description of Input and Examples for Phreeqc Version 3: A Computer Program for Speciation, Batch-reaction, OneDimensional Transport, and Inverse Geochemical Calculations. Createspace Independent Publishing Platform.

Peng, J., Tang, G.-Q., and Kovscek, A. 2009. Oil Chemistry and Its Impact on Heavy Oil Solution Gas Drive. J. Pet. Sci. Eng. 66 (1-2): 47-59. https:// doi.org/10.1016/j.petrol.2009.01.005.

Pierre, A., Lamarche, J. M., Mercier, R. et al. 1990. Calcium as Potential Determining Ion in Aqueous Calcite Suspensions. J. Dispers. Sci. Technol. 11 (6): 611-635. https://doi.org/10.1080/01932699008943286.

Plummer, L. N., Wigley, T. M. L., and Parkhurst, D. L. 1978. The Kinetics of Calcite Dissolution in $\mathrm{CO}_{2}$-Water Systems at 5 degrees to 60 degrees C and 0.0 to $1.0 \mathrm{~atm} \mathrm{CO}_{2}$. Am. J. Sci. 278 (2): 179-216. https://doi.org/10.2475/ajs.278.2.179.

Pokrovsky, O. S., Mielczarski, J. A., Barres, O. et al. 2000. Surface Speciation Models of Calcite and Dolomite/Aqueous Solution Interfaces and Their Spectroscopic Evaluation. Langmuir 16 (6): 2677-2688. https://doi.org/10.1021/la980905e.

Puntervold, T., Strand, S., Ellouz, R. et al. 2015. Modified Seawater as a Smart EOR Fluid in Chalk. J. Pet. Sci. Eng. 133 (September): 440-443. https:// doi.org/10.1016/j.petrol.2015.06.034.

Qiao, C., Johns, R., and Li, L. 2016. Understanding the Chemical Mechanisms for Low Salinity Waterflooding. Presented at SPE Europec featured at the 78th EAGE Conference and Exhibition, Vienna, Austria, 30 May-2 June. SPE-180138-MS. https://doi.org/10.2118/180138-MS. 
Qiao, C., Li, L., Johns, R. T. et al. 2014. A Mechanistic Model for Wettability Alteration by Chemically Tuned Water Flooding in Carbonate Reservoirs. Presented at the SPE Annual Technical Conference and Exhibition, Amsterdam, 27-29 October. SPE-170966-MS. https://doi.org/10.2118/170966MS.

Rezaeidoust, A., Puntervold, T., Strand, S. et al. 2009. Smart Water as Wettability Modifier in Carbonate and Sandstone: A Discussion of Similarities/ Differences in the Chemical Mechanisms. Energ. Fuel. 23 (9): 4479-4485. https://doi.org/10.1021/ef900185q.

Ricci, M., Spijker, P., Stellacci, F. et al. 2013. Direct Visualization of Single Ions in the Stern Layer of Calcite. Langmuir 29 (7): 2207-2216. https:// doi.org/10.1021/la3044736.

Sakuma, H., Andersson, M. P., Bechgaard, K. et al. 2014. Surface Tension Alteration on Calcite, Induced by Ion Substitution. J. Phys. Chem. C 118 (6): 3078-3087. https://doi.org/10.1021/jp411151u.

Salem, M. R., Mangood, A. H., and Hamdona, S. K. 1994. Dissolution of Calcite Crystals in the Presence of Some Metal Ions. J. Mater. Sci. 29 (24): 6463-6467. https://doi.org/10.1007/BF00354005.

Setschenow, Z. 1899. Ueber die Constitution der Salzlösungen auf Grund ihres Verhaltens zur Kohlensäure. Z. Chem. Physik 4: 117-120.

Sheng, J. J. 2014. Critical Review of Low-Salinity Waterflooding. J. Pet. Sci. Eng. 120 (August): 216-224. https://doi.org/10.1016/j.petrol.2014.05.026.

Siffert, D. and Fimbel, P. 1984. Parameters Affecting the Sign and Magnitude of the Eletrokinetic Potential of Calcite. Colloid. Surface. 11 (3-4): 377-389. https://doi.org/10.1016/0166-6622(84)80291-7.

Sjöblom, J., Simon, S., and Xu, Z. 2015. Model Molecules Mimicking Asphaltenes. Adv. Colloid Interf. 218 (April): 1-16. https://doi.org/10.1016/ j.cis.2015.01.002.

Somasundaran, P. and Agar, G. E. 1967. The Zero Point of Charge of Calcite. J. Colloid Interf. Sci. 24 (4): 433-440. https://doi.org/10.1016/00219797(67)90241-X.

Sorbie, K. S. and Collins, I. R. 2010. A Proposed Pore-Scale Mechanism for How Low Salinity Waterflooding Works. Presented at the SPE Improved Oil Recovery Symposium, Tulsa, 24-28 April. SPE-129833-MS. https://doi.org/10.2118/129833-MS.

Sposito, G. 2008. The Chemistry of Soils. Oxford, UK: Oxford University Press.

Strand, S., Høgnesen, E. J., and Austad, T. 2006. Wettability Alteration of Carbonates - Effects of Potential Determining Ions $\left(\mathrm{Ca}^{2+}\right.$ and $\left.\mathrm{SO}_{4}^{2-}\right)$ and Temperature. Colloid. Surface. A 275 (1-3): 1-10. https://doi.org/10.1016/j.colsurfa.2005.10.061.

Stumm, W. and Morgan, J. J. 1996. Aquatic Chemistry: Chemical Equilibria and Rates in Natural Waters, third edition. Environmental Science and Technology. Hoboken, New Jersey: John Wiley \& Sons.

Tang, G.-Q. and Morrow, N. R. 1997. Salinity, Temperature, Oil Composition, and Oil Recovery by Waterflooding. SPE Res Eval \& Eng 12 (4): 269-276. SPE-36680-PA. https://doi.org/10.2118/36680-PA.

Tang, G.-Q. and Morrow, N. R. 1999. Influence of Brine Composition and Fines Migration on Crude Oil/Brine/Rock Interactions and Oil Recovery. J. Pet. Sci. Eng. 24 (2-4): 99-111. https://doi.org/10.1016/S0920-4105(99)00034-0.

Tang, G.-Q. and Morrow, N. R. 2002. Injection of Dilute Brine and Crude Oil/Brine/Rock Interactions. In Environmental Mechanics: Water, Mass and Energy Transfer in the Biosphere, Geophysical Monograph Series, Vol. 129, ed. P. A. C. Raats, D. Smiles, and A. W. Warrick, 171-179. https:// doi.org/10.1029/129GM16.

Thompson, D. W. and Pownall, P. G. 1989. Surface electrical properties of calcite. J. Colloid Interf. Sci. 131 (1): 74-82. https://doi.org/10.1016/00219797(89)90147-1.

Truesdell, A. H. and Jones, B. F. 1974. Wateq, a Computer Program for Calculating Chemical Equilibria of Natural Waters. J. Res. US Geol. Survey 2 (2): 233-274.

Van Cappellen, P., Charlet, L., Stumm, W. et al. 1993. A Surface Complexation Model of the Carbonate Mineral-Aqueous Solution Interface. Geochim. Cosmochim. Ac. 57 (15): 3505-3518. https://doi.org/10.1016/0016-7037(93)90135-J.

Verwey, E. J. W. and Overbeek, J. T. G. 1948. Theory of the Stability of Lyophobic Colloids: The Interaction of Sol Particles Having an Electric Double Layer. New York: Elsevier Publishing Company.

Webb, K., Black, C., and Al-Ajeel, H. 2004. Low Salinity Oil Recovery - Log-Inject-Log. Presented at SPE/DOE Symposium on Improved Oil Recovery, Tulsa, 17-21 April. SPE-89379-MS. https://doi.org/10.2118/89379-MS.

Wolthers, M., Charlet, L., and Van Cappellen, P. 2008. The Surface Chemistry of Divalent Metal Carbonate Minerals: A Critical Assessment of Surface Charge and Potential Data Using the Charge Distribution Multi-Site Ion Complexation Model. Am. J. Sci. 308 (8): 905-941. https://doi.org/10.2475/ 08.2008.02.

Yildiz, H. O. and Morrow, N. R. 1996. Effect of Brine Composition on Recovery of Moutray Crude Oil by Waterflooding. J. Pet. Sci. Eng. 14 (3-4): 159-168 https://doi.org/10.1016/0920-4105(95)00041-0.

Yousef, A. A., Al-Saleh, S., Al-Kaabi, A. et al. 2011. Laboratory Investigation of the Impact of Injection-Water Salinity and Ionic Content on Oil Recovery From Carbonate Reservoirs. SPE Res Eval \& Eng 14 (5): 578-593. SPE-137634-PA. https://doi.org/10.2118/137634-PA.

Zahid, A., Shapiro, A. A., and Skauge, A. 2012. Experimental Studies of Low Salinity Water Flooding Carbonate: A New Promising Approach. Presented at the SPE EOR Conference at Oil and Gas West Asia, Muscat, Oman, 16-18 April. SPE-155625-MS. https://doi.org/10.2118/155625-MS.

Zhang, P. and Austad, T. 2006. Wettability and Oil Recovery from Carbonates: Effects of Temperature and Potential Determining Ions. Colloid. Surface. A 279 (1-3): 179-187. https://doi.org/10.1016/j.colsurfa.2006.01.009.

Zhang, P., Tweheyo, M. T., and Austad, T. 2007a. Wettability Alteration and Improved Oil Recovery by Spontaneous Imbibition of Seawater into Chalk: Impact of the Potential Determining Ions $\mathrm{Ca}^{2+}, \mathrm{Mg}^{2+}$, and $\mathrm{SO}_{4}^{2-}$. Colloid. Surface. A 301 (1-3): 199-208. https://doi.org/10.1016/j.colsurfa.2006.12.058.

Zhang, Y., Xie, X., and Morrow, N. R. 2007b. Waterflood Performance by Injection of Brine With Different Salinity for Reservoir Cores. Presented at the SPE Annual Technical Conference and Exhibition, Anaheim, California, 11-14 November. SPE-109849-MS. https://doi.org/10.2523/109849MS.

Zhang, Y. and Morrow, N. R. 2006. Comparison of Secondary and Tertiary Recovery With Change in Injection Brine Composition for Crude-Oil/Sandstone Combinations. Presented at SPE/DOE Symposium on Improved Oil Recovery, Tulsa, 22-26 April. SPE-99757-MS. https://doi.org/10.2523/99757-MS.

\section{Appendix A-Calcium Carbonate Dissolution Kinetics}

Mineral dissolution occurs in sequential steps, including ion transfer between the crystal-lattice surface and the immediately adjacent aqueous solution, and transport of released solvated ions into bulk aqueous solution. The characteristic time for mineral dissolution/ precipitation, $t_{\mathrm{dis}}$, is the sum of the characteristic reaction and mass-transport times: $t_{\mathrm{dis}}=t_{r x n}+t_{m}$. Equivalently, the resistance to dissolution is the sum of the resistance for mineral-surface ion dislodgement and resistance for flushing dislodged solvated ions into solution. We estimate each characteristic time in order.

To establish $t_{r x n}$, we formulate a simple linear expression for pure calcium carbonate rate of dissolution into aqueous solution, $r_{A}$ $\left(\mathrm{mol} / \mathrm{m}^{2} / \mathrm{s}\right)$. Fig. A-1 illustrates the dissolution process. Our goal is to quantify the intrinsic rate constant $k_{r x n}(\mathrm{~cm} / \mathrm{s})$ from experimental data on $r_{A}$. We begin with the rock equilibrated with brine. 


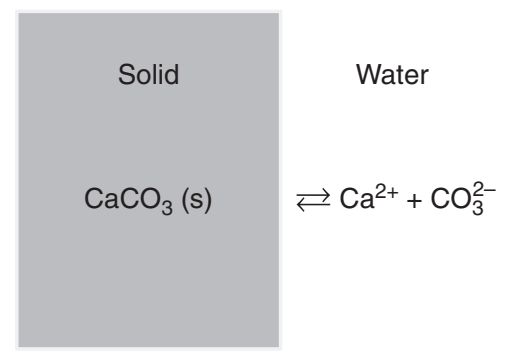

Fig. A-1—Dissolution of solid calcium carbonate into aqueous solvated ions directly at the solid/liquid interface.

Rock/Brine Equilibrium. When the dissolution/precipitation reaction is in equilibrium, as denoted by superscript $e$, reaction equilibrium demands that

$$
\mu_{\mathrm{CaCO}_{3}(s)}=\tilde{\mu}_{\mathrm{Ca}^{2+}}^{e}+\tilde{\mu}_{\mathrm{CO}_{3}^{2-}}^{e}
$$

where subscript $s$ denotes a solid phase, $\mu_{i}$ is the chemical potential of species $i$, and the over tilde indicates an electrochemical potential for an aqueous charged species (Newman and Thomas-Alyea 2004). Because the electrical potential cancels in Eq. A-1, electrochemical potentials of dissolved calcium and carbonate ions are expressed as

$$
\tilde{\mu}_{j}^{e}=\tilde{\mu}_{j}^{\circ}+R T \ln a_{j} j=\mathrm{Ca}^{2+}, \mathrm{CO}_{3}^{2-},
$$

where $a_{j}$ is aqueous-ion $j$ activity, the superscript ${ }^{\circ}$ denotes the infinitely dilute or Henry's standard state in water, $R$ is the ideal-gas constant, and $T$ is absolute temperature. Substitution of Eq. A-2 into A-1 gives the result that

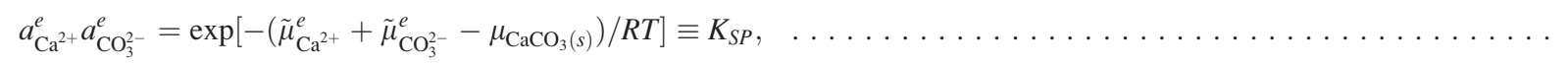

where $K_{S P}$ is the solubility product of calcium carbonate. Eq. A-3 specifies the concentrations of calcium and carbonate ions in equilibrium with calcite. We use this result to formulate the dissolution-kinetic rate expression.

Rock/Brine-Dissolution Kinetics. Deviation from equilibrium drives dissolution. For small deviations, we write that the rate of dissolution scales linearly as the difference between nonequilibrium chemical potentials and those at equilibrium (Lasaga et al. 1994), or

$$
r_{A}=\kappa\left[\left(\tilde{\mu}_{\mathrm{Ca}^{2+}}^{e}+\tilde{\mu}_{\mathrm{CO}_{3}^{2-}}^{e}-\mu_{\mathrm{CaCO}_{3}(s)}\right)-\left(\tilde{\mu}_{\mathrm{Ca}^{2+}}+\tilde{\mu}_{\mathrm{CO}_{3}^{2-}}-\mu_{\mathrm{CaCO}_{3}(s)}\right)\right] / R T,
$$

where the scaling constant $\kappa$ is a function of temperature. By use of Eq. A-2, we re-express Eq. A-4 in the following form:

$$
\left.r_{A}=\kappa\left(\ln a_{\mathrm{Ca}^{2+}}^{e} a_{\mathrm{CO}_{3}^{2-}}^{e}-\ln \left\{a_{\mathrm{Ca}^{2+}}^{e} a_{\mathrm{CO}_{3}^{2-}}^{e}\left[1-\left(a_{\mathrm{Ca}^{2+}} a_{\mathrm{CO}_{3}^{2-}}-a_{\mathrm{Ca}^{2+}}^{e} a_{\mathrm{CO}_{3}^{2-}}^{e}\right) / a_{\mathrm{Ca}^{2+}}^{e} a_{\mathrm{CO}_{3}^{2-}}^{e}\right)\right]\right\}\right) .
$$

Because deviations from equilibrium are small, we obtain

$$
\left(a_{\mathrm{Ca}^{2+}} a_{\mathrm{CO}_{3}^{2-}}-a_{\mathrm{Ca}^{2+}}^{e} a_{\mathrm{CO}_{3}^{2-}}^{e}\right) / a_{\mathrm{Ca}^{2+}}^{e} a_{\mathrm{CO}_{3}^{2-}}^{e} \ll 1 .
$$

Eq. A-6 allows transformation of Eq. A-5 by use of the Taylor expansion to

$$
r_{A}=\kappa\left[1-a_{\mathrm{Ca}^{2+}} a_{\mathrm{CO}_{3}^{2-}} / K_{S P}\right] .
$$

This is one of several rate expressions suggested in the literature (Lasaga et al. 1994; Morse and Arvidson 2002; Sposito 2008). The argument presented previously provides physical justification for this particular rate law in nonideal aqueous solutions. It proves sufficient for estimating $t_{r x n}$ from the measurement of $r_{A}$. Thus, we rewrite Eq. A-7 as

$$
r_{A}=k_{r x n}\left[\sqrt{K_{S P}}-a_{\mathrm{Ca}^{2+}} a_{\mathrm{CO}_{3}^{2-}} / \sqrt{K_{S P}}\right]
$$

where $k_{r x n}=\kappa / \sqrt{K_{S P}}$ (length/time) is the intrinsic dissolution-rate constant. This form of the rate law indicates that dissolution is linear in a "concentration-difference" driving force. The first term in brackets specifies the effective-concentration-driving dissolution, while the second term provides the effective-concentration-driving precipitation. Ion activities in Eq. A-8 correspond to those directly on the aqueous side of the solid/liquid interface. Eq. A-8 does not account for mass-transfer resistance, which is addressed below.

Eq. A-8 permits calculation of the intrinsic dissolution-rate constant, $k_{r x n}$, from the experimental measurements of $r_{A}$. Namely, $k_{r x n}$ equals the measured reaction rate (Plummer et al. 1978; Chou et al. 1989; Lasaga and Luttge 2001; Morse and Arvidson 2002; Palandri and Kharaka 2004; Cubillas et al. 2005) after division by the square root of the calcium-carbonate-solubility product, or $k_{r x n}=r_{A} / \sqrt{K_{S P}}$. The extensive review of Morse and Arvidson (2002) reports $r_{A} \approx 10^{-10} \mathrm{~mol} / \mathrm{cm}^{2} / \mathrm{s}$ for pure calcite at room temperature in nonacidic water and in the presence of environmental $\mathrm{CO}_{2}(\mathrm{~g})$ [see Fig. 10 in Morse and Arvidson (2002) and the references cited therein]. Because the solubility product of calcium carbonate in water (i.e., Reaction 6 in Table 1 ) is $10^{-8.48}(\mathrm{~mol} / \mathrm{L})^{2}$, we find that the intrinsic dissolution-kinetic-rate constant is approximately $10^{-3} \mathrm{~cm} / \mathrm{s}$. With a reported activation energy of $23.5 \mathrm{~kJ} / \mathrm{mol}(\mathrm{Palandri}$ and Kharaka 2004), $k_{r x n}$ weakly increases with temperature by a factor of four between 25 and $75^{\circ} \mathrm{C}$. However, the presence of impurity metals and adsorptive organic materials significantly reduces $k_{r x n}$, possibly by factors of 100 (Salem et al. 1994; Eisenlohr et al. 1999; Arvidson et al. 2003). Because the asphaltenic component of crude oils typically contains both heavy metals and associated organic acids and bases (Peng et al. 2009; Sjöblom et al. 2015), we adopt a range of values for $k_{r x n}$ between $10^{-5}$ and $10^{-3} \mathrm{~cm} / \mathrm{s}$.

Mineral dissolution occurs on exposed surface area. Upon assuming a grain-roughness size along reservoir fractures of $D_{g} \approx 1 \mu \mathrm{m}$, the surface area per unit volume of rock is $a_{V}=6 / D_{g}$ or $a_{V} \approx 6 \times 10^{4} \mathrm{~cm}^{-1}$. Likewise, we assess the characteristic roughness and grain sizes 
in carbonate matrix domains as $\approx 1 \mu \mathrm{m}$. Therefore, the characteristic reaction time for calcium carbonate rock [i.e., $t_{r \times n}=\left(a_{V} k_{r \times n}\right)^{-1}$ ] lies between 15 milliseconds and 1.5 seconds. Molecular kinetic steps occurring at the calcite-aqueous surface are rapid.

Evaluation of $t_{\mathrm{dis}}$ also requires $t_{m}$, the time scale to transport solvated ions away from the mineral surface. This exercise demands consideration of different transport modes depending on the pertinent length scales of the porous medium (Kim and Santamarina 2016). For fractures, the Péclet number, $P e$, is defined as $u \delta / D$ (Bird et al. 2007), where $D$ is the aqueous-salt-diffusion coefficient, typically $10^{-5} \mathrm{~cm}^{2} / \mathrm{s}$, and $u$ is the frontal advance rate approximated here as 10 to $100 \mathrm{ft} / \mathrm{D}$. For either velocity, $P e \gg 1$; mass transport in fractures is convection dominated.

Convection in fractures is quantified here by Darcy flow through a slit of gap thickness, $\delta$. The Graetz theory for plug flow in a slit under fully developed mass transfer (Bird et al. 2007) gives a convective-mass-transfer coefficient of $k_{m} \approx 5 D / \delta$ or $5 \times 10^{-4} \mathrm{~cm} / \mathrm{s}$, which is within the range of the carbonate-surface kinetic-rate constant. The characteristic fracture-mass-transfer time follows from $t_{m}=\left(a_{V} k_{m}\right)^{-1}$ or 30 milliseconds when we adopt a roughness size of $1 \mu \mathrm{m}$. Accordingly, the characteristic dissolution-time constant, $t_{\text {dis }}\left(=t_{r x n}+t_{m}\right)$, ranges from 45 milliseconds to 1.5 seconds, independent of the frontal advance rate.

Conversely, for mass transport away from dissolving grains in matrix zones, the characteristic length appearing in the Péclet number is the grain diameter, chosen here as $\approx 20 \mu \mathrm{m}$. Even for imbibition velocities of $1 \mathrm{ft} / \mathrm{D}, P e<1$. On the pore scale, solvated ion transport is dominated by diffusion. Here, the mass-transfer coefficient $k_{m} \backsim 2 D / D_{g}$ (Bird et al. 2007, page 686) or 0.01 cm/s. Again, assuming a characteristic grain-roughness size of $1 \mu \mathrm{m}$, the characteristic diffusion-time constant in the low-permeability matrix, $t_{m}=\left(a_{V} k_{m}\right)^{-1}$, is 2 milliseconds. We conclude that dissolution time in rock matrix blocks is again $t_{\mathrm{dis}}=45$ milliseconds to 1.5 seconds, independent of the frontal advance rate. For both high- and low-permeability zones of carbonate rocks, the kinetics of rock dissolution is fast, at the longest a few seconds. We use this finding in the main text to establish that local equilibrium sets the carbonate-reservoirbrine composition.

\section{Appendix B-Calcite/Aqueous-Electrolyte Bulk Equilibria}

In this work, we use PHREEQC software with its default database (phreeqc.dat) for calculation of bulk equilibrium speciation. However, the PHREEQC procedure was validated as described here. At equilibrium,

$$
K_{j} \equiv \prod_{i} a_{i}^{\nu_{i j}}=\exp \left(\frac{-\sum \nu_{i j} \mu_{i}^{\circ}}{R T}\right)
$$

where $K_{j}$ is the $j$ th independent reaction equilibrium constants, $a_{i}=\gamma_{i} C_{i}$ is the activity of species $i$, $\mu_{i}^{\circ}$ is the standard-state Gibbs free energy of aqueous species $i$ in the dilute solution or Henry's standard state, $\nu_{i j}$ is the stoichiometric coefficient of species $i$ in reaction $j$, $R$ is the ideal-gas constant, and $T$ is absolute temperature. The exponential argument in Eq. B-1 is a function of temperature only; $\mu_{i}^{\circ}$ for each species is tabulated at standard conditions. Therefore, the exponential argument can be evaluated as a function of temperature by use of the Gibbs-Helmholtz relation and the standard enthalpy of reaction (Felder et al. 2015).

At high $(>1 \mathrm{mM})$ ionic strength, activity coefficients cannot be assumed as unity. Ionic strength of a solution is defined by

$$
I=\frac{1}{2} \sum_{i} z_{i}^{2} C_{i}
$$

where $z_{i}$ is the valence of species $i$ and $C_{i}$ is the molar concentration of charged species $i$. The Davies (1962) equation is used to calculate the activity coefficient for each charged species; it is given as

$$
\log _{10} \gamma_{i}=-A z_{i}^{2}\left(\frac{\sqrt{I}}{1+\sqrt{I}}-0.3 I\right),
$$

where $A$ is a constant that depends only on temperature $\left[0.5085(\mathrm{~mol} / \mathrm{L})^{0.5}\right.$ for $\left.25^{\circ} \mathrm{C}\right]$. For uncharged species, the Setschenow $(1899)$ equation evaluates the activity coefficients:

$$
\log _{10} \gamma_{i}=b_{i} I
$$

where $b_{i}$ is assumed to be $0.1 \mathrm{M}^{-1}$ for all the uncharged species, unless otherwise specified. Along with mass conservation listed in Table B-1 and the solubility product of calcium carbonate (Reaction 6 in Table 1), Eqs. B-1 through B-4 establish the aqueous-speciation-equilibrium concentrations.

The set of eight nonlinear algebraic equations shown in the last column of Table B-1 was programed in MATLAB (2015) and solved for the extent-of-reaction vector $\xi$ by use of the Newton-Raphson method with an $L_{2}$-norm convergence threshold of $10^{-16}$ :

$$
\xi_{i+1}=\xi_{i}-\left[\frac{\mathrm{d} f(\underset{\sim}{\xi})}{\mathrm{d} \underset{\sim}{\xi}}\right]_{i}^{-1} f\left(\xi_{i}\right),
$$

where subscript $i$ denotes the $i$ th iteration.

Constant $\mathrm{CO}_{2}$ pressure was imposed on the system, fixing both $\mathrm{CO}_{2}(\mathrm{aq})$ and $\mathrm{H}_{2} \mathrm{CO}_{3}$ concentrations. Ionic-strength variation resulting from dissolution of calcite or $\mathrm{CO}_{2}$ was iterated in the Davies equation (Eq. B-3) until less than a 5\% difference was reached. This value was then used to convert concentrations to activities. The vector of initial guesses for the Newton-Raphson algorithm was $10^{-4}$ for all concentrations.

To compare the MATLAB results with PHREEQC software, the default database was changed to run simulations with the Davies activity correction. The MATLAB code and PHREEQC gave identical results. After validation, the PHREEQC software was used to calculate bulk speciation for all species shown in Table B-1 at both low and high ionic strengths. PHREEQC uses extended DebyeHückel equations (applicable from 0 to $0.1 \mathrm{~mol} / \mathrm{L}$ ionic strength) or WATEQ extended Debye-Hückel equations, which allow for activity correction at higher ionic strengths (Truesdell and Jones 1974):

$$
\log _{10} \gamma_{i}=-\frac{A z_{i}^{2} \sqrt{I}}{1+B a_{i}^{o} \sqrt{I}}+b_{i} I,
$$


where $z_{i}$ is the valence of aqueous species $i$, and $A$ and $B$ are constants dependent only on temperature $\left[0.5085(\mathrm{~mol} / \mathrm{L})^{0.5}\right.$ and 3.3 $\left(\mathrm{mol} \mathrm{nm}{ }^{2} / \mathrm{L}\right)^{-0.5}$, respectively, at $\left.25^{\circ} \mathrm{C}\right], I$ is ionic strength, and $\gamma_{i}$ is activity coefficient. If $b_{i}=0$, Eq. B-6 is the extended Debye-Hückel equation; otherwise, it is the WATERQ extended Debye-Hückel. In the extended Debye-Hückel equation, $a_{i}^{0}$ is the ion-size parameter, whereas in the WATERQ extended Debye-Hückel equation, $a_{i}^{0}$ and $b_{i}$ are ion-specific parameters fitted from the mean salt-activitycoefficient data. In the PHREEQC database (see the PHREEQC standard database, phreeqc.dat), these parameters are specified for each ion. If they are not present, PHREEQC resorts to the extended Debye-Hückel or to the Davies (1962) equation. For uncharged species, $A$ is zero, and Eq. B-6 reduces to the Setschenow (1899) equation (Eq. B-4); the $b_{i}$ parameter is specified for each species.

\begin{tabular}{|c|c|c|}
\hline Definitions & Mass-Balance Equations ${ }^{*}{ }^{* *}$ & Equilibrium Equations \\
\hline$C_{1}=\left[\mathrm{CO}_{2}(\mathrm{aq})\right]$ & $C_{1}=P_{\mathrm{CO}_{2}} K_{1}$ & $\log _{10} \gamma_{i}=-A z_{i}^{2}\left(\frac{\sqrt{I}}{1+\sqrt{I}}-0.3 I\right)$ \\
\hline$C_{2}=\left[\mathrm{H}_{2} \mathrm{CO}_{3}\right]$ & $C_{2}=C_{1} K_{2}$ & For charged species \\
\hline$C_{3}=\left[\mathrm{HCO}_{3}^{-}\right]$ & $C_{3}=C_{3}^{0}+\xi_{1}-\xi_{2}+\xi_{6}+\xi_{7}$ & $\log _{10} \gamma_{i}=b I$ \\
\hline$C_{4}=\left[\mathrm{CO}_{3}^{2-}\right]$ & $C_{4}=C_{4}^{0}+\xi_{2}-\xi_{4}+\xi_{8}$ & For uncharged species \\
\hline$C_{5}=\left[\mathrm{H}^{+}\right]$ & $C_{5}=C_{5}^{0}+\xi_{1}+\xi_{2}+\xi_{3}$ & $K_{3} C_{2} \gamma_{2}-\left(C_{3} \gamma_{3}\right)\left(C_{5} \gamma_{5}\right)=0$ \\
\hline$C_{6}=\left[\mathrm{OH}^{-}\right]$ & $C_{6}=C_{6}^{0}+\xi_{3}+\xi_{5}$ & $K_{4} C_{3} \gamma_{3}-\left(C_{4} \gamma_{4}\right)\left(C_{5} \gamma_{5}\right)=0$ \\
\hline$C_{7}=\left[\mathrm{Ca}^{2+}\right]$ & $C_{7}=C_{7}^{0}+\xi_{4}+\xi_{5}+\xi_{6}$ & $K_{5}-\left(C_{5} \gamma_{5}\right)\left(C_{6} \gamma_{6}\right)=0$ \\
\hline$C_{8}=\left[\mathrm{Na}^{+}\right]$ & $C_{8}=C_{8}^{0}+\xi_{7}+\xi_{8}$ & $K_{6}-\left(C_{4} \gamma_{4}\right)\left(C_{7} \gamma_{7}\right)=0$ \\
\hline$C_{9}=\left[\mathrm{Cl}^{-}\right]$ & $C_{9}=C_{9}^{0}$ & $K_{7}\left(C_{10} \gamma_{10}\right)-\left(C_{6} \gamma_{6}\right)\left(C_{7} \gamma_{7}\right)=0$ \\
\hline$C_{10}=\left[\mathrm{CaOH}^{+}\right]$ & $C_{10}=C_{10}^{0}-\xi_{5}$ & $K_{8}\left(C_{11} \gamma_{11}\right)-\left(C_{3} \gamma_{3}\right)\left(C_{7} \gamma_{7}\right)=0$ \\
\hline$C_{11}=\left[\mathrm{CaHCO}_{3}^{+}\right]$ & $C_{11}=C_{11}^{0}-\xi_{5}$ & $K_{9}\left(C_{12} \gamma_{12}\right)-\left(C_{3} \gamma_{3}\right)\left(C_{8} \gamma_{8}\right)=0$ \\
\hline$C_{12}=\left[\mathrm{NaHCO}_{3}\right]$ & $C_{12}=C_{12}^{0}-\xi_{7}$ & $K_{10}\left(C_{13} \gamma_{13}\right)-\left(C_{4} \gamma_{4}\right)\left(C_{8} \gamma_{8}\right)=0$ \\
\hline$C_{13}=\left[\mathrm{NaCO}_{3}^{-}\right]$ & $C_{13}=C_{13}^{0}-\xi_{8}$ & - \\
\hline
\end{tabular}

*The numbering on extents in the Mass-Balance Equations column refers to the reaction numbers in Table 1 but shifted by two, so that Reaction 3 in Table 1 corresponds to $\xi_{1}$.

${ }^{* *}$ In the Mass-Balance Equations column, the superscript 0 denotes inlet or initial concentrations.

Table B-1-List of equations used in validation of the PHREEQC calculation.

\section{Appendix C-Surface-Calcite/Aqueous-Electrolyte Equilibria}

Let $\sigma_{0}, \sigma_{\beta}$, and $\sigma_{d}$ denote the surface-charge densities in Fig. 4 at the calcite surface, at the $\beta$-plane, and in the diffuse layer extending outward from the $d$-plane, respectively. Overall electroneutrality demands that $\sigma_{0}+\sigma_{\beta}+\sigma_{d}=0$. However, the crystal structure of calcite at the (104)-face specifies that the density of calcium-lattice ions at the surface be the same as that of surface-carbonate-lattice ions; therefore, $\sigma_{0}$ is zero. Thus, the governing relation for the SCM is

$$
\sigma_{\beta}+\sigma_{d}=0 \text {. }
$$

We must specify these two surface-charge densities. To quantify $\sigma_{\beta}$, equilibrium-site-binding chemical reactions are introduced. As discussed in the text, we chose the five preliminary surface reactions listed in Table 2, where $>$ denotes surface ions. As illustrated in the text, mass-action equations are applied to each of the five site-binding reactions. These are rewritten as follows:

$$
\begin{aligned}
& K_{S 1}\left(>\mathrm{CaH}_{2} \mathrm{O}^{+}\right)-(>\mathrm{CaOH}) \gamma_{\mathrm{H}^{+}} C_{\mathrm{H}^{+}} \exp \left[\frac{-F \varphi_{\beta}}{R T}\right]=0, \ldots . \\
& K_{S 2}\left(>\mathrm{CaH}_{2} \mathrm{O}^{+}\right) \gamma_{\mathrm{HCO}_{3}^{-}} C_{\mathrm{HCO}_{3}^{-}}-\left(>\mathrm{CaHCO}_{3}\right) \exp \left[\frac{-F \varphi_{\beta}}{R T}\right]=0, \\
& K_{S 3}\left(>\mathrm{CaH}_{2} \mathrm{O}^{+}\right) \gamma_{\mathrm{CO}_{3}^{2-}} C_{\mathrm{CO}_{3}^{2-}}-\left(>\mathrm{CaCO}_{3}^{-}\right) \exp \left[\frac{-2 F \varphi_{\beta}}{R T}\right]=0, \\
& K_{S 4}\left(>\mathrm{CO}_{3}^{-}\right) \gamma_{\mathrm{H}^{+}} C_{\mathrm{H}^{+}}-\left(>\mathrm{CO}_{3} \mathrm{H}\right) \exp \left[\frac{F \varphi_{\beta}}{R T}\right]=0, \ldots . \\
& K_{S 5}\left(>\mathrm{CO}_{3}^{-}\right) \gamma_{\mathrm{Ca}^{2+}} C_{\mathrm{Ca}^{2+}}-\left(>\mathrm{CO}_{3} \mathrm{Ca}^{+}\right) \exp \left[\frac{2 F \varphi_{\beta}}{R T}\right]=0, \ldots .
\end{aligned}
$$

where curved parentheses () denote surface concentrations in number (sites) per unit area, and $\varphi_{\beta}$ is the electrostatic potential at the $\beta$-plane. To understand the origin of the $\beta$-plane electrostatic potential appearing in Eqs. C- 2 through C- 6 , we write the excess chemical potential for each surface species at the 0 - and $\beta$-planes as $R T \ln (>S i)_{0}+z_{i} F \varphi_{0}$ and $R T \ln (>S i)_{\beta}+z_{i} F \varphi_{\beta}$, respectively, where $(>S)_{0}$ 
and $\left(>S_{i}\right)_{\beta}$ denote species $i$ surface concentrations in the 0 - and $\beta$-planes. Substitution of these relations into reaction-equilibria criteria provides Eqs. C-2 through C-6 because $\varphi_{\beta}=\varphi_{0}$ because of the calcite-surface-lattice electroneutrality. The surface-complexing equilibrium constants, $K_{S_{i}}$, are listed in Table 2 . Reaction equilibria at ion-exchange sites are augmented by conservation of total sites or

$$
\begin{aligned}
& \Gamma_{\max }=\left(>\mathrm{CaH}_{2} \mathrm{O}^{+}\right)+\left(>\mathrm{CaHCO}_{3}\right)+\left(>\mathrm{CaCO}_{3}^{-}\right)+(>\mathrm{CaOH}), \\
& \Gamma_{\max }=\left(>\mathrm{CO}_{3}^{-}\right)+\left(>\mathrm{CO}_{3} \mathrm{Ca}^{+}\right)+\left(>\mathrm{CO}_{3} \mathrm{H}\right), \ldots \ldots \ldots
\end{aligned}
$$

where $\Gamma_{\max }=5 \mathrm{~nm}^{-2}$ is the equal anion- and cation-exchange capacities of the calcite-lattice surface. Not all ions can reach this maximal value. $\Gamma_{\max }$ for large ions, for example $\mathrm{Zn}^{2+}$, should be corrected to consider steric limitations (Davis and Kent 1990). Finally, charge density at the $\beta$-plane is defined by the surface concentrations of specifically adsorbed charged ions, as illustrated in Fig. 3 :

$$
\frac{\sigma_{\beta}}{F}=\left(>\mathrm{CO}_{3} \mathrm{H}\right)+2\left(>\mathrm{CO}_{3} \mathrm{Ca}^{+}\right)-(>\mathrm{CaOH})-\left(>\mathrm{CaHCO}_{3}\right)-2\left(>\mathrm{CaCO}_{3}^{-}\right) .
$$

Next, the expression for the surface-charge density in the diffuse layer, $\sigma_{d}$, is obtained from the Poisson-Boltzmann equation written for constant dielectric permittivity (Verwey and Overbeek 1948; Newman and Thomas-Alyea 2004; Berg 2010):

$$
\varepsilon \frac{\mathrm{d}^{2} \varphi}{\mathrm{d} x^{2}}=-\sum_{i} z_{i} F C_{i} \exp \left[\frac{-z_{i} F \varphi(x)}{R T}\right],
$$

where the linear coordinate $x$ extends from the 0 -plane. Eq. C-10 is rearranged to

$$
\frac{\mathrm{d}}{\mathrm{d} x}\left(\frac{\mathrm{d} \varphi}{\mathrm{d} x}\right)^{2}=-\frac{2 F}{\varepsilon} \sum_{i} z_{i} C_{i} \exp \left[\frac{-z_{i} F \varphi}{R T}\right]\left(\frac{\mathrm{d} \varphi}{\mathrm{d} x}\right),
$$

and integrated subject to boundary conditions of the asymptotic approach to zero potential far from the surface. The result is

$$
\left(\frac{\mathrm{d} \varphi}{\mathrm{d} x}\right)^{2}=\frac{2 R T}{\varepsilon} \sum_{i} C_{i}\left\{\exp \left[\frac{-z_{i} F \varphi}{R T}\right]-1\right\} .
$$

Evaluation of Eq. C-12 by Gauss' law at the $d$-plane [i.e., $\sigma_{d}=-\varepsilon(\mathrm{d} \varphi / \mathrm{d} x)_{d}$ ] provides Eq. 6 in the main text. We replace the bulk relative permittivity of water by an average value of 50 over the distance from the $d$-plane to infinity. The final step is a relation between potentials $\varphi_{\beta}$ and $\varphi_{d}$, which follows from Poisson and Gauss:

$$
\varphi_{\beta}-\varphi_{d}=-\frac{\sigma_{d}}{\bar{C}_{2}}
$$

where $\bar{C}_{2}$ is the constant integral capacitance between the inner and outer Helmholtz planes. $\bar{C}_{2}$ is determined by the ratio of the local dielectric permittivity to the width of the region. We adopt a relative dielectric constant of 15 in this region, which has a width of $0.22 \mathrm{~nm}$. As listed in Table 3, an integral capacitance of $13 \mu \mathrm{F} / \mathrm{cm}^{2}$ emerges, a physically acceptable value.

Given the bulk aqueous-species concentrations from Appendix B, Eqs. 6, C-1 through C-9, and C-13 are solved by Newton iteration in MATLAB for the variables $\sigma_{d}, \varphi_{\beta}, \varphi_{d}$ and the seven surface-species concentrations in Table 2.

Maxim Yutkin is a research scientist at ANPERC at KAUST. He pursued a post-doctoral-degree appointment in South Korea and then joined one of Schlumberger's Engineering and Development centers, where he worked on development of fracturing fluids. Yutkin's research interests span widely from functional materials to surface chemistry and interfacial phenomena to chemical interactions and flow-dynamics subsurface, including oil reservoirs. He has authored or coauthored more than 20 publications in scientific journals and patent literature. Yutkin has been an SPE member since 2012. He holds a PhD degree in chemistry.

Himanshu Mishra is an assistant professor of environmental science and engineering and a principal investigator at the Water Desalination and Reuse Center at KAUST. Before attaining this position, he was an Elings Prize post-doctoral-degree fellow in Jacob Israelachvili's group at the University of California, Santa Barbara. Mishra's research program at KAUST is focused on understanding physics and chemistries at interfaces of water and hydrophobic media to address challenges in enhanced oil recovery, membrane distillation, and desert agriculture. He has authored or coauthored more than 13 journal articles and holds two patents. Mishra holds a PhD degree in materials science and engineering from California Institute of Technology.

Tadeusz Patzek is a professor of chemical and petroleum engineering and director of the Upstream Petroleum Engineering Center at KAUST. Until December 2014, he was chair of the Petroleum and Geosystems Engineering Department at the University of Texas at Austin. Patzek's research involves mathematical and numerical modeling of Earth systems with emphasis on subsurface fluid flow. He has authored or coauthored more than 250 technical papers, two patents, and one book, and his blog has 300,000 unique readers. Patzek is an SPE Distinguished Member.

John Lee worked as an engineering intern for 6 months in the aerospace industry. His research interests include catalysis and reactions, biotechnology, and sustainable energy. Lee holds a bachelor's degree in chemical engineering from the University of California, Berkeley.

Clayton (Clay) J. Radke is a professor of chemical and biomolecular engineering at the University California, Berkeley. His research focuses on interfacial and colloidal technologies. Radke has published more than 270 research monographs, has coauthored one book, holds three patents, and has delivered more than 700 technical papers. He won the Proctor \& Gamble Colloid Chemistry Award of the American Chemistry Society in 2003, the 2011 SPE John Franklin Carl Award, the Chemstations Research Lectureship Award of the American Society for Engineering Education in 2013, and the University of Washington Alumnus of the Year in 2015. Radke was elected to the National Academy of Engineering in 2015. 